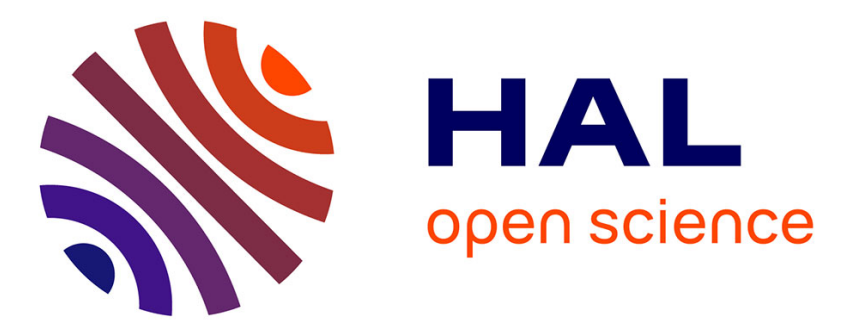

\title{
The interplay between overriding plate kinematics, slab dip and tectonics
}

\author{
Nestor G. Cerpa, Benjamin Guillaume, Joseph Martinod
}

\section{To cite this version:}

Nestor G. Cerpa, Benjamin Guillaume, Joseph Martinod. The interplay between overriding plate kinematics, slab dip and tectonics. Geophysical Journal International, 2018, 215 (3), pp.1789-1802. $10.1093 /$ gji/ggy365 . insu-01874223

\section{HAL Id: insu-01874223 \\ https://hal-insu.archives-ouvertes.fr/insu-01874223}

Submitted on 14 Sep 2018

HAL is a multi-disciplinary open access archive for the deposit and dissemination of scientific research documents, whether they are published or not. The documents may come from teaching and research institutions in France or abroad, or from public or private research centers.
L'archive ouverte pluridisciplinaire HAL, est destinée au dépôt et à la diffusion de documents scientifiques de niveau recherche, publiés ou non, émanant des établissements d'enseignement et de recherche français ou étrangers, des laboratoires publics ou privés. 


\title{
The interplay between overriding plate kinematics, slab dip and tectonics
}

\author{
N. G. Cerpa ${ }^{1,2 \star}$, B. Guillaume ${ }^{3}$, J. Martinod ${ }^{4}$.
}

1 Department of Earth Sciences, University of Oxford, South Parks Road, Oxford, OX1 3AN,

United-Kingdom

2 Now at Univ. Montpellier, Geosciences Montpellier, UMR CNRS 5243, Montpellier F-34095, France

3 Univ. Rennes, CNRS, Géosciences Rennes - UMR 6118, Rennes F-35000, France.

4 Univ. Savoie Mont Blanc, Univ. Grenoble Alpes, CNRS, IRD, IFSTTAR, ISTERRE, 73376 Le Bourge du Lac, France. 


\section{SUMMARY}

In subductions where the slab stagnates at the 660-km mantle discontinuity, overriding plate kinematics largely controls slab dip and overriding plate tectonics. Although plates kinematics models suggest frequent velocity changes for most plates, the impact of temporal evolution of overriding plate velocity on subduction dynamics has been relatively little addressed. In the present study, we use 2-d numerical models to assess the effects of changes in overriding plate far-field velocity on subduction geometry and on the horizontal stresses transmitted to the overriding plate. When a change in overriding plate velocity arises during slab stagnation, slab dip evolves during a transient period, called adjustment-time, to reach a state in equilibrium with the new boundary conditions. The models predict a dependency of the adjustment-time on the value of velocity change and on several internal parameters (subducting plate density, thickness, and viscosity, and mantle viscosity). We estimate that the adjustment-times may be $\sim 10-35$ Myrs in Nature, which suggests that most of present-day subduction zones with stagnating slabs might not be at a steady-state. Further, the models predict that changes in overriding plate velocity generate high temporary variations in the state of stresses of the plate.

Key words: Plate kinematics, Subduction dynamics, slab dip, tectonics 


\section{INTRODUCTION}

Present-day subduction zones exhibit a relatively wide range of subducting slab geometries (Lallemand et al. 2005; Goes et al. 2017) that reflects a diversity in the dynamical evolution of each individual subduction system. Several factors may impact subduction dynamics including subducting plates'/mantle's strength and subducting plate buoyancy (Bellahsen et al. 2005; Stegman et al. 2010; Funiciello et al. 2003; Schellart 2008a; Ribe 2010), slabmantle transition zone interaction (Č́žžková and Bina 2013; Gibert et al. 2012; Agrusta et al. 2017; Billen and Hirth 2007), regional and global mantle circulation (Doglioni et al. 1999; Schellart et al. 2007; Funiciello et al. 2004; Ficini et al. 2017; Faccenna et al. 2013), or the nearby presence of other subduction zones (Király et al. 2016; Holt et al. 2017). The overriding plate has also been shown to play a key role in subduction dynamics (Yamato et al. 2009; Capitanio et al. 2010; van Dinther et al. 2010; Butterworth et al. 2012; Gibert et al. 2012; Rodríguez-González et al. 2012; Garel et al. 2014; Sharples et al. 2014; Holt et al. 2015). In particular, the overriding plate motion relative to the subducting plate has been shown to influence the slab geometry in dynamic models of subduction with prescribed kinematic boundary conditions (Heuret et al. 2007; Guillaume et al. 2009; Gibert et al. 2012; Cerpa et al. 2014).

In Nature, the relationship between slab dip and velocity of the overriding plate was revealed by different statistical studies on present-day subduction zones (Jarrard 1986; Lallemand et al. 2005; Heuret et al. 2007). Yet, these studies reported relatively low correlations coefficients (e.g. $R=0.56$ in Heuret et al. (2007)), contrasting with the results of modeling studies (e.g. $R=0.89$ in Heuret et al. (2007)). Part of this poor correlation may result from the effects of the various other parameters that influence the dynamics of subduction. Furthermore, while the models assumed perfectly anchored slab at the mantle transition zone and a subduction at a steady-state, present-day subductions span a wide range of states (from subducting slabs that have not yet reached the 660-km discontinuity to slabs well penetrating into the lower mantle (e.g. Fukao and Obayashi 2013)), which may also 
contribute to the relatively low correlations in Nature. Near-edge effects or uncertainties in kinematic models have also been proposed for the apparent discrepancy between models and data. Further, recent variations in plate kinematics may produce subduction systems at unsteady-state which could increase the lack of correlation between present overriding plate velocity and observed subduction geometry (Guillaume et al. 2018).

The variations in plate motions over geological timescales may be driven by regional and/or global phenomena (Zahirovic et al. 2015; Sdrolias and Müller 2006; Müller et al. 2016). The arrival of plumes heads (Zahirovic et al. 2015), the reorganization of global plate kinematics after the break-up of major plates (e.g. Farallon, (Pardo-Casas and Molnar 1987)), or the collision between large continent-supporting plates (e.g. collision between India and Eurasia, (Jolivet et al. 1999)) may have induced important changes in plate kinematics. Further, the change in mantle circulation flow induced by the transition from an upper to a lower mantle subduction may also promote a change in the trenchward motion of overriding plates as it has been proposed for the South-American subduction (Husson et al. 2012; Faccenna et al. 2017).

Despite the potential role of past kinematic variations on the state of present-day subductions, their effects on subduction dynamics has been relatively little explored by quantitative models. They are however among the mechanisms proposed to explain the evolution of orogens in regions such as the Andes. Silver et al. (1998) suggested that a westward acceleration of the South-American plate triggered Andean orogeny although other authors rather emphasized the role of changes in convergence velocity (e.g. Pardo-Casas and Molnar 1987). Changes in kinematics may have also induced the flattening of the Nazca plate which, in turn, may have induced periods of compression, shortening and thickening of the continental crust (Haschke et al. 2006). In fact, most subduction zones have undergone changes in overriding plate and/or convergence velocity during the last 50 Myrs that may have caused variations in the tectonic regime of the overriding plate in different regions (Sdrolias and 
Müller 2006). Understanding the consequences of changes in plates kinematics on subduction dynamics appears thus to be crucial to decipher actual observations.

How does a subduction system accommodate sudden changes in overriding plate motion? What is the feedback on overriding plate tectonics? Recently, Guillaume et al. (2018) have addressed those questions using 3-D subduction laboratory models. They showed that a transient stage in the subduction system follows an instantaneous acceleration/deceleration of the overriding plate. During the transient stage, slab dip decreases in the case of an acceleration, and increases in the case of a deceleration. Based on their modeling results, the authors suggested that the transient stage for deep slab dip (at $\sim 300-\mathrm{km}$ depth) may last in average $\sim 29.2 \pm 10$ Myrs with little dependency on the magnitude of variation in overriding plate kinematics.

The present study is a complement to the recent work of Guillaume et al. (2018) and aims to decipher the controls on the evolution of subduction geometry following changes in overriding plate motion using 2-D numerical models. By doing so, we explore whether the changes in overriding plate kinematics may be a key factor on the dynamical evolution of subduction zones.

We first address the case of a constant overriding plate velocity. Second, we study models of subduction where a variation in overriding plate velocity is imposed. While Guillaume et al. (2018) only studied the influence of the magnitude of change in overriding plate velocity, here we perform a parametric study on a wider range of parameters that we divide into two different kinds : external parameters (e.g. magnitude of changes in overriding plate velocity, instantaneous vs. progressive changes in overriding plate velocity) and internal parameters (e.g. rheological parameters, subducting plate thickness). For each parameter we apply a range of realistic values that may represent a range of different subduction settings. Finally, we assess the consequences of changes in slab dip during the transient stage on the overriding plate tectonics. 


\section{MODELING APPROACH}

Our approach to model subduction dynamics is based on the assumption that the lithospheric plates behave as (Maxwell) viscoelastic solid bodies and the mantle behaves as a Newtonian fluid. This "solid-fluid coupling" approach has been previously used in several studies (Bonnardot et al. 2008; Morra and Regenauer-Lieb 2006; Capitanio et al. 2007; Goes et al. 2011). Here, we adopt the novel method of Cerpa et al. (2014) to tackle the coupled problem. In this section, we recall the governing equations of the mechanical problem and describe the model set-up.

\subsection{Governing equations}

The governing equations for the quasi-static evolution of lithospheric plates occupying at time $t$ a physical domain $\Omega_{l}^{t} \subset \mathbb{R}^{2}$ are

$$
\begin{aligned}
& \nabla \cdot \boldsymbol{\sigma}+\rho_{l} \boldsymbol{g}=\mathbf{0} \quad \text { in } \Omega_{l}^{t}, \\
& \frac{D \boldsymbol{\sigma}}{D t}=2 G \boldsymbol{d}+\lambda \operatorname{tr} \boldsymbol{d} \boldsymbol{I}-\frac{G}{\eta_{l}} \operatorname{dev} \boldsymbol{\sigma} \text { in } \Omega_{l}^{t},
\end{aligned}
$$

where $\boldsymbol{\sigma}$ is Cauchy stress tensor, $\boldsymbol{g}$ is gravity acceleration vector, and $\rho_{l}$ is density of lithospheric plates. The symbol $D \cdot / D t$ describes an objective time derivative. $\boldsymbol{d}=\frac{1}{2}\left(\nabla \dot{\boldsymbol{u}}+\nabla \dot{\boldsymbol{u}}^{T}\right)$ is Eulerian strain rate tensor with $\dot{\boldsymbol{u}}$ the velocity field in the plates. tr and $\mathbf{d e v}$ are the trace and deviatoric parts of a second order tensor, respectively. $\boldsymbol{I}$ is identity tensor. $\lambda$ and $G$ are the Lamé parameters and $\eta_{l}$ is viscosity of the lithospheric plates. Note that if $\eta \rightarrow \infty$, Eq. (2) describes Hooke's law.

The contact between the two lithospheric plates or between a plate and a rigid foundation is described by the Signorini contact conditions defined with a Coulomb friction law as

$$
\left\{\begin{array}{l}
\delta \dot{u}_{n} \leq 0, \sigma_{n} \leq 0, \delta \dot{u}_{n} \sigma_{n}=0 \quad \text { on } \Gamma_{c}, \\
\left|\sigma_{t}\right| \leq-\mu \sigma_{n} \text { if } \delta \dot{u}_{t}=0 \quad \text { on } \Gamma_{c}, \\
\sigma_{t}=\mu \sigma_{n} \frac{\delta \dot{u}_{t}}{\left|\delta \dot{u}_{t}\right|} \text { if } \delta \dot{u}_{t} \neq 0 \quad \text { on } \Gamma_{c},
\end{array}\right.
$$


where $\delta \dot{u}_{n}$ and $\delta \dot{u}_{t}$ are the normal and tangential components, respectively, of the relative velocity between a point on plate's surface and its projection onto the other plate or onto the rigid foundation (i.e. onto the contact interface $\Gamma_{c}$ ), $\mu$ is Coulomb friction coefficient, $\sigma_{n}$ and $\sigma_{t}$ are normal and tangential stresses, respectively.

In the mantle (domain $\Omega_{m} \subset \mathbb{R}^{2}$ ), we solve the incompressible Stokes equations and we use a Newtonian constitutive law :

$$
\begin{array}{rc}
\boldsymbol{\nabla} \cdot \boldsymbol{\tau}+\boldsymbol{\nabla} P+\rho_{m} \boldsymbol{g}=0 & \text { in } \Omega_{m}, \\
\boldsymbol{\nabla} \cdot \boldsymbol{v}=0 & \text { in } \Omega_{m}, \\
\boldsymbol{\tau}=2 \eta_{m} \dot{\boldsymbol{\epsilon}} & \text { in } \Omega_{m}
\end{array}
$$

where $\boldsymbol{\tau}$ is the deviatoric stress tensor, $\boldsymbol{v}$ is velocity field, $P$ total pressure. $\rho_{m}$ is density of mantle and $\eta_{m}$ its viscosity. $\dot{\boldsymbol{\epsilon}}=\frac{1}{2}\left(\nabla \boldsymbol{v}+\nabla \boldsymbol{v}^{T}\right)$ is strain-rate tensor.

On the plates-mantle interfaces $\Gamma_{l m}$ continuity of the traction vector is required (principle of action-reaction) and we assume continuity of velocity fields (full-coupling) :

$$
\left\{\begin{array}{l}
(\boldsymbol{\tau}+P \boldsymbol{I}) \cdot \boldsymbol{n}=\boldsymbol{\sigma} \cdot \boldsymbol{n} \text { on } \Gamma_{l m} \\
\boldsymbol{v}=\dot{\boldsymbol{u}} \quad \text { on } \Gamma_{l m}
\end{array}\right.
$$

where $\boldsymbol{n}$ is unit vector normal to $\Gamma_{l m}$ with outwards orientation relative to $\Omega_{l}^{t}$.

\section{$2.2 \quad$ Model set-up}

Our 2-D mechanical models consist of two (visco)elastic plates (overriding plate : OP; subducting plate : SP) separated by a pre-defined fault and an isoviscous upper mantle (Fig. 1). We use dynamic models with prescribed boundary conditions on the far-field edges of the lithospheric plates while their top surfaces remain "free" (free-stress condition). We prescribe a rigid rough barrier (no-slip condition) at the bottom of the upper mantle (i.e. the transition zone assumed at a 660-km depth) in order to achieve a perfect anchored subducting slab. This boundary condition is consistent with the relative large viscosity jump 
predicted at the mantle transition zone which may favor slab flattening and anchoring, i.e. slab stagnation, at the 660-km depth discontinuity in a number of natural subduction zones (Goes et al. 2017, and references therein). Lateral mantle boundaries are open. In most of our models, we impose the overriding plate velocity on its far-field edge (see Fig. 1). It may either remain constant or vary during the model-time to explore the effects of a change in overriding plate motion on the dynamics of subduction. We also consider a few complementary models where the overriding plate is "free" (free-deviatoric stress condition applied on the trailing edge of the overriding plate), hereafter referred to as free-overriding plate models. Finally, we consider only models with fixed subducting plates to prevent the appearance of cyclic variations in slab geometry (Gibert et al. 2012; Cerpa et al. 2014), isolating thus the effects of variations in overriding plate velocity on the dynamics of the system and on slab dip . Such an idealized configuration may more generally be encountered in subduction systems where the overriding plate moves relatively fast compared to the subducting plate ( $v_{o p} \gtrsim 3 v_{s p}$, see Fig. S1 in Supp. Info.), but the effects of variations in overriding plate velocity on slab geometry is likely to occur beyond these scenarios. However, the quantification of simultaneous dynamic effects of both slab folding and changes in overriding plate motion is beyond the scope of our paper.

To compute the discretized problem we use the code ADELIM (Cerpa et al. 2014, 2015) that couples a 2D-FEM solid solver (Hassani et al. 1997) and a 2D-FEM Stokes solver using a fictitious domain method. Additional information about model set-up and numerical discretization can be found in the Supporting Information. The reader is also referred to Cerpa et al. (2014) for a detailed description of the numerical method.

Throughout this study we monitor the models kinematically (overriding plate/trench velocity) and geometrically ( $\operatorname{slab} \operatorname{dip} \theta$ ). The trench velocity $v_{\text {trench }}$ is the horizontal velocity of the rightmost point at the top of the overriding plate, and is equal to the overriding plate velocity in models with negligible horizontal deformation of the overriding plate. In the free- 
overriding plate models, $v_{o p}$ is the velocity measured at the trailing edge of the overriding plate. Previous works have made a distinction between a "shallow slab dip" (above a 125-km depth) and a "deep slab dip" (below a 125-km depth)(Lallemand et al. 2005). The latter was suggested to control the overriding plate tectonics in present-day subduction zones as it may represent the general interplay between the forces acting on the system. We therefore focus our study on the evolution of this quantity. Throughout the manuscript we refer the "deep slab dip", averaged between 200 and 400-km depth (i.e. slab dip at a 300-km depth), to as simply "slab dip".

\section{CONSTANT OVERRIDING PLATE VELOCITY AND SLAB DIP}

We assess the relationship between the overriding plate velocity and slab dip in models where overriding plate velocity is constant through time. We consider idealized models (Models A) with negligible overriding plate horizontal deformation by assuming that it behaves elastically $\left(\eta_{o p} \rightarrow \infty\right)$. This ensures a perfect match between the overriding plate far-field velocity $v_{o p}$ and trench velocity $v_{\text {trench }}$. The subducting plate is viscoelastic $\left(\eta_{s p}=10^{24} \mathrm{~Pa} \mathrm{~s}\right)$. Density contrast at the base of the $70-\mathrm{km}$ thick plates is $50 \mathrm{~kg} \cdot \mathrm{m}^{-3}$. The viscosity of the upper mantle is $10^{20} \mathrm{~Pa}$ s. Friction at the plates' interface is neglected. Other model parameters are reported in Table S1 in the Supporting Information. We also consider a complementary free-overriding plate Model Afree (with parameters identical to those of Models A).

We define a reference model (Model A3.0, Fig. 2) with a constant overriding plate velocity of $3 \mathrm{~cm} / \mathrm{yr}$. After the forced subduction initiation, the subducting slab sinks into the mantle as the overriding plate moves trenchwards. In this first stage of subduction, slab dip increases until the slab reaches the base of the upper mantle as a result of an increase in slab pull (Fig. 2a-b). The first interaction between the slab and the 660-km discontinuity causes a transient variation in slab dip (Fig. 2c). Then, the subducting slab anchors at the base of the upper mantle and the slab is deposited horizontally as the slab rollbacks. During 
the deposition of the slab, that we refer to as slab stagnation, slab dip tends towards an asymptotic state (i.e. slab dip time-evolution with constant slope; Figs. 2d-e) which is a quasi steady-state.

We compute three models identical to the reference Model A3.0 except that we prescribe constant overriding plate velocities of 2.5, 3.6, and $4.2 \mathrm{~cm} / \mathrm{yr}$ (Models A2.5, A3.6, and A4.2, respectively). Similar to Model A3.0, the slab dip in Model A2.5 and Model 3.6 reaches a quasi-steady state after slab anchoring at 660-km depth but slightly decreases with time in Model A4.2 (Fig. 3a). As expected when slab stagnates, the higher the overriding plate velocity, the lower the slab dip.

To infer a relationship between slab dip and overriding plate velocity after slab anchoring, we compute the time-averaged slab dip over the last 20 Myrs $(\bar{\theta})$, that is then referred to as mean slab dip, for each Model A and perform a linear regression. We find that

$$
\bar{\theta}=-6.3 v_{o p}+82.7
$$

with $\bar{\theta}$ in degrees and $v_{o p}$ in $\mathrm{cm} / \mathrm{yr}$ (Fig. 4; see also Fig. S2). The correlation coefficient is $R^{2} \sim 1$ 1.0. Although slightly shifted, the measured slab dip after slab anchoring in Model Afree exhibits a similar trend than that inferred from our Models A with a prescribed $v_{o p}$ (open circles in Fig. 4). It is important to note that the values of $v_{o p}$ that we have imposed in Models A are always lower than the velocity that the overriding plate (trench) would have in the free-overriding plate model. The latter velocity is then referred to as free-overriding plate velocity (free-trench velocity).

\section{OVERRIDING PLATE VELOCITY VARIATIONS AND SLAB DIP}

We now investigate the effects of changes in overriding plate velocity on slab dip. Here again, horizontal deformation of the overriding plate is neglected $\left(\eta_{o p} \rightarrow \infty\right)$ as we want to isolate 
and quantify the effects of solely the variations in overriding plate velocity. Moreover, we focus the study on the dynamics during slab stagnation.

In what follows, each model is assigned a name $\mathrm{X} w$ or $\mathrm{X} w \_y$ where $\mathrm{X}$ is a letter, $w$ (and $y$ if applies) a number. $\mathrm{X}$ refers to a given set of models while $w$ (and $y$ ) indicate(s) the applied overriding plate velocity in $\mathrm{cm} / \mathrm{yr}$. For instance, in Model $\mathrm{X} w$ we apply a constant velocity $v_{o p}=w$ to the overriding plate. In Model $\mathrm{X} w_{-} y$ we apply a velocity of $v_{o p}=w$ during a first stage of the model, and at a given time $t_{v a r}$ we change the applied velocity to reach $v_{o p}=y$ during a second stage of the model. We define the change in overriding plate velocity $\Delta v_{o p}=y-w$. Other model parameters of Models Xw and Models X $w \_y$ are identical, and are given Table S1 in Supp. Info.

\subsection{Influence of external parameters}

\subsubsection{Influence of the value of $\Delta v_{o p}$}

We first study models where an instantaneous increase $\Delta v_{o p}>0$ in overriding plate velocity is applied (Models A3.0_3.6, A3.0_4.2, A2.5_3.0, and A2.5_4.2; Fig. 5) and compare them to models with constant $v_{o p}$ (Models A2.5, A3.0, A3.6, and A4.2). Slab dip in Models Aw_y is identical to slab dip in Models Aw before the change in overriding plate velocity occurs. When boundary conditions are changed, slab dip decreases, and after a transient stage, tends towards the slab dip in Model Ay (Fig. 5a).

As shown by Guillaume et al. (2018), when applying an instantaneous acceleration to the overriding plate, slab dip is suddenly higher than the value expected at equilibrium with the new boundary conditions. Therefore, the slab dip decreases during a certain time, that we hereafter refer to as adjustment-time $\left(\Delta T_{\theta}\right)$, to adjust to the new equilibrium state. To estimate the adjustment-times in the models described above, we follow the approach used by Guillaume et al. (2018) and we assume that the time-evolution of slab dip during the transient stage follows an exponential decay. We thus compute the difference in slab dip 
$(\Delta \theta)$ between slab dip in Model $\mathrm{A}_{w_{-}} y$ and slab dip in Model Ay after $t_{v a r}$, and we fit the results with an exponential function of form

$$
\Delta \theta(t)=a \mathrm{e}^{-\left(t-t_{\text {var }}\right) / \tau}+b
$$

where $\tau$ is the characteristic time of the function. We then assume that $3 \tau$, that is the time after which $95 \%$ of the asymptotic value has been reached, corresponds to the adjustmenttime and we find that $\Delta T_{\theta}$ in Models A3.0_3.6, A3.0_4.2, A2.5_3.0, A2.5_4.2 is 18.9, 17.2, 17.8, and 15.6 Myrs, respectively. The larger the acceleration, the smaller the adjustmenttime.

Considering now models where an instantaneous velocity decrease $\Delta v_{o p}<0$ is imposed (Models A3.6_3.0, A4.2_3.0, A3.0_2.5, and A4.2_2.5; Fig. S4 in Supp. Info.), we observe opposite behaviors of slab dip during the transient stage compared to models where an acceleration is imposed. During the transient stage in Model Aw_y where the overriding plate velocity decreases from $w$ to $y(w>y)$, the slab dip is lower than expected at equilibrium with the new kinematic condition $y$. Therefore, slab dip increases during the transient stage. We estimate the adjustment-time of slab dip for these "decelerated" models and find that adjustment-time increases with the absolute value of velocity decrease. The adjustmenttimes range between 22 and 28 Myrs. We also observe that for the same absolute change in overriding plate velocity the adjustment-time for a decelerated model is higher than that of an "accelerated" model.

We perform a linear regression to estimate the relationship between adjustment-times $\left(\Delta T_{\theta}\right)$ and the value of change in overriding plate velocity $\left(\Delta v_{o p}\right)$ for Models $\mathrm{A} w_{-} y$ presented above (Fig. 6, black dots and line). The regression gives

$$
\Delta T_{\theta}\left(\Delta v_{o p}\right)=-3.5 \Delta v_{o p}+20.8
$$

where $\Delta T_{\theta}$ is in Myrs and $\Delta v_{o p}$ in $\mathrm{cm} / \mathrm{yr}$. The correlation coefficient is $R^{2}=0.96$. The fitted value of $\Delta T_{\theta}$ at $\Delta v_{o p}=0$ might indicate the existence of an "intrinsic time" of the 
system, that is a minimum time needed for the system to adjust infinitesimal variations in boundary conditions. Adding additional Models A3.0_3.15, A3.15_2.85 with relatively small absolute changes in overriding plate velocity $\left(\Delta v_{o p}=0.15 \mathrm{~cm} / \mathrm{yr}\right)$, and Model A2.5_5.5 with a relatively large change $\left(\Delta v_{o p}=3.0 \mathrm{~cm} / \mathrm{yr}\right), \Delta T_{\theta}$ and $\Delta v_{o p}$ still exhibit a good correlation but the correlation coefficient of the linear regression decreases $\left(R^{2}=0.89\right.$ - Fig. 6, grey dots and line). Note that our method to estimate the adjustment-time becomes less accurate for small changes (the change in slab dip during the adjustment-time in Models A3.0_3.15 and A3.0_2.85 is less than $1^{\circ}$ ).

Further, we measure the total change in slab dip during the adjustment-time and we find a linear correlation between this value and the change in overriding plate velocity (Fig. 7). As expected from the results of models with a constant overriding plate velocity, large changes in overriding plate velocity lead to large variations in slab dip.

\subsubsection{Gradual increase in overriding plate velocity}

In Nature, plate kinematics reconfigurations, i.e. changes in boundary conditions for subduction systems, may not be instantaneous and possibly last several Myrs. To assess the effects of a gradual change in boundary conditions we perform three additional models where the overriding plate velocity increases linearly over a time $\Delta T_{\text {var }}$. We study three cases : Model A3.0_3.6_05, Model A3.0_3.6_10 and Model A3.0_3.6_20 where overriding plate increases from 3 to $3.6 \mathrm{~cm} /$ yr over 5, 10 and 20 Myrs, respectively (Fig. 8a). All other model parameters are fixed and remain identical to the parameters of Model A3.0_3.6.

The value of $\Delta T_{\text {var }}$ changes the pattern of slab dip evolution during the transient stage (Fig. 8b). A sharp exponential-shaped evolution is observed when the change in kinematic boundary conditions is instantaneous or relatively fast (Models A3.0_3.6 and A3.0_3.6_05) while a flatter evolution curve is observed in Models A3.0_3.6_10 and A3.0_3.6_20. Importantly, we observe that, even at a relatively small rate of change in $v_{o p}$ (Models A3.0_3.6_10 and A3.0_3.6_20), slab dip still varies after the new boundary condition has been reached 
(i.e. after $\left.t_{\mathrm{var}}+\Delta T_{\mathrm{var}}\right)$. We define $\left(\Delta T_{\theta}^{\prime}\right)$ as the time for slab dip to reach an equilibrium state after the new boundary condition has been reached (at $t_{v a r}+\Delta T_{\text {var }}$ ). It is estimated using the exponential-fit described in Section 4.1.1 and we find :

- For Model A3.0_3.6_05 : $\Delta T_{\theta}^{\prime}=17.4$ Myrs

- For Model A3.0_3.6_10 : $\Delta T_{\theta}^{\prime}=18.3$ Myrs

- For Model A3.0_3.6_20: $\Delta T_{\theta}^{\prime}=12.7$ Myrs

The computed $\Delta T_{\theta}^{\prime}$ does not display any apparent trend with $\Delta T_{\text {var }}$. In fact, $\Delta T_{\theta}^{\prime}$ in Model A3.0_3.6_20 exhibits a lower $\Delta T_{\theta}^{\prime}$ than in the two other models but this might be due to an underestimate of $\Delta T_{\theta}^{\prime}$ in Model A3.0_3.6_20 because of the small changes in slab dip in this model after $t_{\mathrm{var}}+\Delta T_{\mathrm{var}}\left(\sim 1^{\circ}\right)$. In any case, our numerical models always predict a non-zero value for $\Delta T_{\theta}^{\prime}$, which is close to the $\Delta T_{\theta}$ for model with an instantaneous acceleration (Model A3.0_3.6: 18.9 Myrs). We interpret this result as an additional evidence of the existence of an "intrinsic-time" previously introduced.

\subsection{Influence of internal parameters}

We now study the effects of internal parameters on the adjustment-time for slab dip after a change in boundary conditions $\left(v_{o p} \in[3.0 ; 4.2] \mathrm{cm} / \mathrm{yr}\right)$. For each internal parameter considered, we run a set of models consisting of models where a constant overriding plate velocity is applied and models where we instantaneously increase the overriding plate velocity at a given time $t_{\mathrm{var}}$. The models are compared to Models A3.0_3.6 and A3.0_4.2. The studied internal parameters are :

- density contrast at the base of the subducting plate $(\Delta \rho$, Models B and C)

- subducting plate viscosity $\left(\eta_{s p}\right.$, Models D and E)

- mantle viscosity $\left(\eta_{m}\right.$, Models F and $\left.\mathrm{G}\right)$

- initial subducting plate thickness $\left(h_{s p}^{0}\right.$, Models J, K and L)

- friction at plates' interface ( $\mu$, Models $\mathrm{M}, \mathrm{N}$ and $\mathrm{O}$ ) 
The results of each set of models with imposed overriding plate velocities are given in the Supp. Info. (Section S2.4; Fig. S5 to S10). Here, we rather focus on the estimated adjustment-times $\Delta T_{\theta}$ in models where we apply an instantaneous change in $v_{o p}$ (Fig. 9; see also Fig. S11). Our modeling results show that the adjustment-time $\Delta T_{\theta}$ decreases with $\Delta \rho$ (Fig. 9a) and $h_{s p}$ (Fig. 9b). There is no apparent correlation between $\Delta T_{\theta}$ and $\mu$ (Fig. 9c) in the relatively small range of considered values. $\Delta T_{\theta}$ appears to increase almost linearly with $\eta_{s p}$ (Fig. 9d) and $\eta_{m}$ (Fig. 9e). No correlation has been found between $\Delta T_{\theta}$ and the plates'-to-mantle viscosity ratio (see results Models H and I in Supp. Info). Moreover, we have found a very weak correlation between the adjustment-time and the total change in slab dip during the adjustment-time for the entire set of models (coefficient of linear correlation is $R=0.34-$ Fig. S12).

\section{OVERRIDING PLATE VELOCITY VARIATIONS, SLAB DIP AND OVERRIDING PLATE TECTONICS}

Lallemand et al. (2005) observed that the dip of the slab and stresses in the overriding plate are correlated in Nature. Here, in order to assess the influence of kinematic-induced slab dip variations on overriding plate tectonics, we consider models where the overriding plate is viscoelastic and can horizontally deform $\left(v_{o p} \neq v_{\text {trench }}\right)$.

\subsection{The effects of overriding plate deformation on kinematic-induced slab dip variations}

We perform two models with a constant overriding plate velocity of $3 \mathrm{~cm} / \mathrm{yr}$ and a viscoelastic overriding plate Model Aa3.0 ( $\left.\eta_{o p}=10^{24} \mathrm{~Pa} \mathrm{~s}\right)$ and Model Ab3.0 $\left(\eta_{o p}=2.5 \times 10^{23} \mathrm{~Pa} \mathrm{~s}\right)$, that we compare to the reference Model A3.0 with an elastic overriding plate (Fig. 10). After slab anchoring, slab dip reaches a quasi-steady state in Model Aa3.0 and decreases with time in Model Ab3.0 (Red lines - Fig. 10a). The evolution of slab dip in those models correlates with the evolution of trench velocity ( $\left.v_{\text {trench }}\right)$ through time (Red lines - Fig. 10b). 
While in Model Aa3.0, $v_{\text {trench }}$ is slightly higher than $v_{o p}$ but remains relatively constant, in Model Ab3.0, we observe an increase in $v_{\text {trench }}$ after slab anchoring. This is due to the fact that when the overriding plate is relatively weak (e.g. in Model Ab3.0), it is stretched and thus $v_{\text {trench }}>v_{o p}$. In the latter case, slab dip becomes controlled by trench velocity. Model Ab3.6 with a constant overriding plate velocity of $3.6 \mathrm{~cm} / \mathrm{yr}$ and a relatively weak overriding plate shows a similar rate of increase in $v_{\text {trench }}$ to that in Model Ab3.0.

We then perform models where overriding plate velocity increases instantaneously from $3 \mathrm{~cm} / \mathrm{yr}$ to $3.6 \mathrm{~cm} / \mathrm{yr}$ at $t_{\text {var }}$ (Model Aa3.0_3.6 and Model Ab3.0_3.6) and from $3 \mathrm{~cm} / \mathrm{yr}$ to $4.2 \mathrm{~cm} / \mathrm{yr}$ (Model Aa3.0_4.2). We estimate the adjustment-times for slab $\operatorname{dip}\left(\Delta T_{\theta}\right)$ and find values of 19.8 and 21.6 Myrs for Model Aa3.0_3.6 and Model Ab3.0_3.6, respectively. Although slightly higher, those values are close to the adjustment-time calculated for Model A3.0_3.6 with an infinitely strong overriding plate $\left(\Delta T_{\theta}=18.9\right.$ Myrs $)$. Similarly, the adjustment-time is 18.8 Myrs for Model Aa3.0_4.2 and 17.2 Myrs for Model A3.0_4.2. Those results suggest that the internal deformation of the overriding plate does not play a first-order effect on slab dynamics during the transient stage following a kinematic variation.

\subsection{Kinematic-induced slab dip variations and overriding plate tectonics}

We now illustrate the effects of variations in slab dip on overriding plate tectonics. First, we consider models without friction at the plates' interface (Aa3.0, Aa4.2, and Aa3.0_4.2) for which we calculate a horizontal force inland within the overriding plate $F_{x x}$ (Fig. 11). $F_{x x}$ is considered positive when the overriding plate is in extension.

As described previously for models with a constant overriding plate velocity (Models Aa3.0 and Aa4.2), the models tend towards an equilibrium state after slab anchoring, and the horizontal force $F_{x x}$ tends towards an asymptotic value that is positive, indicating an overriding plate in extension. Although the observed differences are small, the mean $F_{x x}$ is slightly lower in Model Aa4.2 than in Model Aa3.0. Extension of the overriding plate can be 
explained by the imposed overriding plate velocities being smaller than that of free-overriding plate velocity $\left(v_{o p} \simeq 8-11 \mathrm{~cm} / \mathrm{yr}\right.$ in Model Aafree; Fig. S3). As a matter of fact, the higher velocity of Model Aa4.2 compared to Model Aa3.0, induces a lower $F_{x x}$ (lower extension). In Model Aa3.0_4.2, we impose an instantaneous increase in $v_{o p}$ at $t_{v a r}=49.5$ Myrs. In this model, we observe a sudden decrease in $F_{x x}$ that reaches its minimum value at $\sim 5$ Myrs after $t_{v a r}$ (at $\sim 1 / 4$ of the estimated $\Delta T_{\theta}$ ). This minimum value of $F_{x x}$ is $1-2 \times 10^{12} \mathrm{~N} / \mathrm{m}$ lower than the value before acceleration. $F_{x x}$ then increases to finally tend towards a mean value that is equivalent to the mean value of $F_{x x}$ in Model Aa4.2.

Next, we realize the same comparison for Models $\mathrm{Na}$ where a relatively high friction coefficient $\mu=0.05$ is imposed at the plates' interface (all other model parameters are identical to that of their equivalent Models Aa). Similar trends are observed in Models Na compared to Models Aa except that the values of $F_{x x}$ are shifted towards the negative values (compression). A complementary free-overriding plate model (Models Nafree, Fig. S3) indicates that our imposed overriding plate velocities are close to the free-overriding plate velocity $\left(v_{o p} \simeq 3-4 \mathrm{~cm} / \mathrm{yr}\right)$, explaining the tectonic regimes observed in Models $\mathrm{Na}$ with constant $v_{o p}$. In Model Na3.0_4.2, a decrease of maximum $2 \times 10^{12} \mathrm{~N} / \mathrm{m}$ is also observed after the overriding plate acceleration. Then, $F_{x x}$ increases again and tends towards an asymptote. During the adjustment-time, we observe an important period of relatively high compression following the overriding plate acceleration.

In Models $\mathrm{Aa}$ and $\mathrm{Na}$ with variable $v_{o p}$, the maximum change in $F_{x x}$ is reached when the absolute value of the derivative of slab dip is the highest (Fig. 11b). In these models, the variation in slab dip is $\simeq 8.5^{\circ}\left(\bar{\theta}=60.6^{\circ}\right.$ in Model Na3.0 vs. $\bar{\theta}=63.9^{\circ}$ in Model Aa3.0 and $\bar{\theta}=52.1^{\circ}$ in Model Na4.2 vs. $\bar{\theta}=55.3^{\circ}$ in Model Aa4.2) and adjustment-times are $\sim 20$ Myrs but, as previously shown, the rate of change in slab dip could be higher, or lower, depending on the values of external and internal parameters. In any case, following a change in overriding plate velocity, the dip of the slab needs to adapt to the new kinematic 
boundary conditions. As a result, a tectonic pulse occurs within the overriding plate during this adjustment period.

\section{DISCUSSION}

\subsection{Constant overriding plate velocity and slab dip}

In the present study, we have modeled subduction systems with advancing overriding plates (retreating trenches), and stagnating slabs. Slab folding has been prevented by fixing the far-field edge of the subducting plates (Gibert et al. 2012). Trench retreat may dominate on Earth (e.g. Funiciello et al. 2008), which may, in turn, favor slab stagnation (Christensen 1996; Garel et al. 2014). Although, stagnating slabs may penetrate into the lower mantle after a few dozens of Myrs (Goes et al. 2017), we have considered a perfect impermeable barrier at a $660-\mathrm{km}$ depth. Despite this limitation, our models address the relationship between overriding plate kinematics and slab dip following the observations of Lallemand et al. (2005) who showed that slab dip and slab age at trench are not correlated in present-day subduction zones (see also Cruciani et al. 2005). Rather, they showed that slab dip correlates to both the absolute overriding plate velocity and the absolute trench velocity (see also Heuret et al. 2007), specially for slabs that have reached the mantle transition zone and for transects far from the lateral edges of the slab. Nonetheless, these authors found relatively low coefficients of correlation (e.g. $R=0.4$ for overriding plate velocity vs. slab dip in Lallemand et al. (2005) and $R=0.56$ in Heuret et al. (2007)). The relationship between slab dip and overriding plate velocity during slab stagnation has also been investigated in laboratory experiments. The analog models exhibit a linear relationship with relatively high correlation coefficients $\left(R^{2}=0.89\right.$ in Heuret et al. (2007), $R^{2}=0.90$ in Guillaume et al. (2018)), exploring a relatively wide range of kinematic boundary conditions. Performing a linear regression for the mean slab dip measured in our Models A with prescribed overriding plate velocities we find a perfect correlation with the far-field overriding plate velocity $\left(R^{2}=0.999\right)$. The very high correlation coefficient calculated in our models between the mean slab $\operatorname{dip} \bar{\theta}$ and overriding plate velocity $v_{o p}$ relative to that of previous analog models 
is likely due to the fact that all model parameters except the overriding-plate velocity are perfectly fixed in Models A. The same calculation for another set of model parameters also exhibits a perfect linear correlation between $\bar{\theta}$ and $v_{o p}$ (Fig S2a). Conversely, performing a linear regression of the $\bar{\theta}$ measured in all models with constant overriding plate velocity, we find that $\bar{\theta}$ and $v_{o p}$ are poorly correlated (Fig S2b) because of the effects of the other model parameters.

The linear relationship (Eq. (8)) between $\bar{\theta}$ and $v_{o p}$ derived from our Models $\mathrm{A}$ is consistent with the relationship determined by Guillaume et al. (2018). Further, for all the set of model parameters that we have tested, we find that the slope of $\bar{\theta}$ as a function of $v_{o p}$ is $\sim 6-8^{\circ} \mathrm{cm}^{-1} \mathrm{yr}$. Note that these trends are derived from models where the overriding plate is not allowed to deform horizontally $\left(\eta_{s p} \rightarrow \infty\right)$ whereby $v_{o p}=v_{\text {trench. }}$. Our models with a deformable overriding plate rather suggest that slab dip evolution is controlled by $v_{\text {trench }}$, in accordance with previous works in which trench velocity was either imposed (Olbertz et al. 1997; Griffiths et al. 1995) or was the result of a "free-subduction" system (Schellart 2004). In fact, we observe that models with a relatively strong overriding plate $\left(\eta_{o p}=10^{24} \mathrm{~Pa} \mathrm{~s}\right)$ exhibit a slab dip evolution that is similar to that of the idealized models with infinitely strong overriding plates. In contrast, in models with a relatively weak overriding plate, the control of far-field overriding plate velocity on slab dip becomes less important, and slab dip evolves during trench migration. In the latter case, other parameters become key control on slab dip as discussed below.

Models of subduction with free overriding-plates show that, in slab retreating subductions, slab dip is controlled by the buoyancy and the resistance to bending of the subducting slab (Ribe 2010; Schellart 2004; Stegman et al. 2010). Our free-overriding plate model (Model Afree) with a relatively strong subducting plate $\left(\eta_{s p}=10^{24} \mathrm{~Pa} \mathrm{~s}\right)$ is consistent with previous models as it produces relatively fast slab rollback and trench retreat ( $\left.v_{\text {trench }} \simeq 9-10 \mathrm{~cm} / \mathrm{yr}\right)$, similarly e.g. to the "Strong Retreat" mode of subduction in Ribe 
(2010). Also, Model Afree shows that the evolution of slab dip vs. overriding plate velocity in a free-overriding plate model follows the same trend as the linear relationship derived from the mean slab dip and the imposed $v_{o p}$ in Models Aw (Fig. 4), although the imposed velocities are lower than the free- $v_{o p}$. This shows the dynamic consistency between free-overriding plate models and models with a prescribed $v_{o p}$. In the latter case, the prescribed overriding plate advance induces a resistance to the trench retreat produced by the slab pull, and partly controls slab dip. Note that we have also modeled cases (Models N,Na) where the imposed velocities are close to the free-velocities. In some of theses models, the prescribed plate advance forces a faster trench retreat than the one that would be induced only by slab pull.

In Nature, estimating how much the overriding plates impedes the "free" evolution of subduction zones (i.e. imposes a trench motion faster or slower than the free trench motion) is difficult to quantify. Several works have shown that the overriding plate velocity is correlated with both the geometry of the slab and the state of the stresses in the back-arc, which advocates for the role played by the motion of the overriding plate onto the dynamics of subduction zones (Heuret and Lallemand 2005; Lallemand et al. 2005). For our modeling purposes, we assume that a subduction segment and the motion of the corresponding overriding plate segment results from a 3-D balance. Then, part of theses forces are far-field relative to the studied subduction segment. They constraint the velocity of the overriding plate that we impose in our models to quantify the effects of a kinematic variation. Previous works have proposed that the motion of subducting plates on Earth are mostly controlled by their slab pull (e.g. Goes et al. 2011), and thus may be better modeled as "free" plates. Nonetheless, in order to better quantify the effects of a variation in overriding plate's kinematics, we have chosen to model a fixed subducting plate. The general modeling results (necessary adjustment-time, pulse in tectonic forces) discussed below should however also apply on top of the own dynamics of subduction zones with a mobile subducting plate. 


\subsection{Adjustment-time of slab dip following instantaneous changes in overriding plate velocity}

Guillaume et al. (2018) recently addressed the effects of changes in the plates' kinematic boundary conditions on slab dip. They observed a poor correlation between the value of the change in overriding plate velocity and the adjustment-time. They, however, only investigated a relatively small range of changes in overriding plate velocity $\left(1.2<\Delta v_{\text {op }}<\right.$ $1.6 \mathrm{~cm} / \mathrm{yr})$. In the present study, we have expanded the range of changes in velocity and we deduce from our models a linear relationship, negatively sloped, between the adjustmenttime $\Delta T_{\theta}$ and the overriding plate velocity change $\Delta v_{o p}$ (all other model parameters are fixed).

We find that 1 ) the higher the increase in $v_{o p}$ (acceleration) the shorter the adjustmenttime, and 2) the higher the decrease in $v_{o p}$ (slow-down) the longer the adjustment-time. The decrease in adjustment-time with $\Delta v_{o p}$ in accelerated models is likely due to the fact that in those models the change in overriding plate velocity brings the overriding plate velocity closer to the free-overriding plate velocity (see Fig. 4). The opposite occurs in decelerated models. In other words, the accommodation of slab dip is facilitated if the change shifts the slab towards its "free configuration". Yet, we do not observe any correlation of adjustmenttime with the value of overriding plate velocity before or after the change. This suggests that the adjustment-times are controlled by the absolute value of the change $\left|\Delta v_{o p}\right|$ rather than by $v_{o p}$.

For the smallest $\Delta v_{o p}$ for which we can estimate the adjustment-time, we find values higher than 15 Myrs, suggesting that even for small changes in the kinematic boundary conditions, there is an non-zero 'intrinsic time' for the system to adjust to new boundary conditions. This hypothesis cannot be further investigated with our approach since our method to determine $\Delta T_{\theta}$ becomes inefficient for changes in slab dip smaller than $1^{\circ}$ (e.g. for velocity changes $<0.15 \mathrm{~cm} / \mathrm{yr}$ based on our empirical relation (10)). As shown by the models of Guillaume et al. (2018), the adjustment-time does not correlate with the convergence 
velocity, and thus we argue that this "intrinsic time" exhibited by our models is unlikely to reflect the time needed for the perturbation to propagate from the surface to the depth at which slab dip is measured. Conversely, this "intrinsic time" also depends on the model parameters as shown in Fig. S11 (higher $\Delta T_{\theta}$ at $\Delta v_{o p}=0.0$ for Models $\mathrm{E}$ than for Models A as inferred from regression line).

We have explored the influence of internal model parameters on the adjustment-time in Section 4.2. For a fixed value of change in overriding plate velocity, the adjustment-time increases with plates' and mantle viscosities (Models D,E,F, and G), and decreases with density contrast (Models B and C) and subducting plate thickness (Models J,K, and L). As discussed for Models A above, the variations in adjustment-time observed with varying the internal parameters is unlikely to be controlled by the corresponding differences between imposed overriding plate velocity and free-overriding plate velocity. Instead, our results suggest that the internal parameters may directly affect the response of the slab after a change in overriding plate velocity.

The viscosity of the subducting plate controls its resistance to bending (slab stiffness (e.g. ?Stegman et al. 2010)) and thus controls the rate at which slab dip can vary following a change in boundary conditions, that is a change in the torque applied to the subducting slab at the plate interface. Similarly, lateral displacements of the subducting slab (e.g. during an increase or a decrease in slab dip) is resisted by the viscosity of the mantle which therefore has a similar control on the slab dip adjustment-time.

The effects of $\Delta \rho$ are less straightforward. We can nonetheless observe that the relationship between adjustment-time and the total change in slab dip during the adjustment-time exhibits a relatively good correlation coefficient if one only considers the models with various $\Delta \rho$ (Fig. S12). Increasing slab density forces the slab to remain fairly steep regardless of the overriding plate velocity, preventing large variations in slab dip during the adjustment-times 
(Fig. S5). Thus, an increase in $\Delta \rho$ produces a decrease in adjustment-time.

The thickness of the subducting plate controls both the slab stiffness $\left(\sim \eta_{s p} h_{s p}^{3}\right)$ and its volumetric potential energy $\left(\sim \Delta \rho g h_{s p}\right)$ which induce opposite effects on slab dip. Models with the same constant $v_{o p}$ confirm that slab thickness has a major effect on slab stiffness as a thin subducting plate displays higher slab dip than a thick suducting plate (see Fig. S9). However, models with an overriding plate velocity variation show that increasing slab thickness decreases the total change in slab dip during the transient stage, and may thus explain the decrease of adjustment-time with $h_{s p}$.

\subsection{Slab dip adjustment-time and implications for the study of natural subduction zones}

\subsubsection{Slab-dip adjustement-times in Nature}

In Models A, we have tested variations in overriding plate velocity up to $3.0 \mathrm{~cm} / \mathrm{yr}$ while plate reconstruction models for Cenozoic suggest changes up to $10 \mathrm{~cm} / \mathrm{yr}$ in Nature (Sdrolias and Müller 2006). Nonetheless, in the last $20 \mathrm{Ma}$, changes in plates velocities may have been on average less than $1 \mathrm{~cm} / \mathrm{yr}$ for most subduction zones as revealed by the estimation of changes in overriding plate velocities for 5-Myrs intervals in the last $20 \mathrm{Ma}$ from the model of Müller et al. (2016) (Fig. 12). Using the mean value of changes during each 5-Myrs interval and the empirical relation Eq. (10), we predict average adjustment-times (assuming instantaneous changes in velocity) in Nature of 17.9, 18.9, 20.6, and 18.9 Myrs for the 0-5, 5-10, 10-15, and 15-20-Myrs intervals, respectively, for subductions with overriding plates that have accelerated. The same calculation for subductions with overriding plates that have decelerated predicts adjustment-times between 21 and 23 Myrs.

Models with a gradual change in overriding plate velocity show that for changes in boundary conditions that last more than $\sim 5$ Myrs, the total adjustment-time of slab $\operatorname{dip}\left(\Delta T_{\theta}\right)$ is always greater than the duration of the change in boundary conditions $\Delta T_{\text {var }}$. After the new 
boundary condition has been reached, slab dip stabilizes only after $10-20$ Myrs and does not show any particular trend with the duration $\Delta T_{\text {var. }}$ In Nature, kinematic variations due to global plates reconfigurations may have lasted several Myrs (e.g. Zahirovic et al. 2015) but the duration of changes in overriding plate velocity is difficult to constrain. Therefore, it is possible that subduction systems with a stable overriding plate velocity in the last $10 \mathrm{Ma}$ may still be accommodating kinematic changes that may have occurred in the last 10-30 Ma.

Based on their results, Guillaume et al. (2018) concluded that the adjustment-times for slab dip in Nature may be about 20-40 Myrs. Here, by varying the internal model parameters, we predict more variability in adjustment-times. Our end-member models (e.g. highest values of subducting plate viscosity) exhibit values of $\Delta T_{\theta}$ as high as 60 Myrs, and one might expect that the diversity of subduction zones could undergo a wide range of adjustment-times. In order to test this hypothesis we first empirically derive a linear relationship between the adjustment-time and the studied internal parameters (Fig. 13) from models in Section 4.2:

$$
\Delta T_{\theta} \simeq 2.34 \Lambda-0.40
$$

where $\Lambda=\frac{\sqrt{\eta_{s p} \eta_{m}}}{\Delta \rho g h_{s p}}\left(\Lambda\right.$ in Myrs). The correlation coefficient is $R^{2}=0.70$.

We then consider end-members subducting plates in terms of age and average strength to predict average adjustment-times in Nature. We use the relationship between the lithosphere thickness and the age of the plate proposed by Turcotte and Schubert (2002):

$$
h_{s p}[\text { in } \mathrm{m}]=2.32 \times \sqrt{\kappa A}
$$

where $\kappa=7.5 \times 10^{-7} \mathrm{~m}^{2} \mathrm{~s}^{-1}$ is the average lithosphere thermal diffusivity and $A$ is the plate age (in s), to calculate the thickness of a relatively young (30 Ma, the 25th percentile of present-day subducting plates' age at trench in the SUBMAP database (Heuret and Lallemand 2005)) and a relatively old (110 Ma, the 75th percentile of present-day subducting plates' age at trench in the SUBMAP database) subducting plate. The lithosphere average density contrast is inferred from the model of Cloos (1993) for a noneclogitized oceanic crust, and is 25 and $46 \mathrm{~kg} \mathrm{~m}^{-3}$ for the young and the old plates, respectively. We assume 
an average upper mantle viscosity of $4 \times 10^{20} \mathrm{~Pa}$ s (Mitrovica and Forte 2004; Paulson et al. 2007; Lau et al. 2016). The subducting plate viscosity is chosen in accordance to previously proposed values for the effective viscosity ratio between slab and surrounding mantle in Nature [45;700] (Funiciello et al. 2008; Schellart 2008a; Wu et al. 2008; Ribe 2010; Loiselet et al. 2009). Moreover, we assume that young slabs are likely to be relatively weak and their viscosity is assumed to be $[45 ; 350]$ times higher than the upper mantle while old slabs are likely stronger and we thus assume a viscosity ratio of [350;700]. We predict an adjustmenttime of $\Delta T_{\theta} \in[12.9 ; 36.6]$ Myrs for young and weak slabs, and $\Delta T_{\theta} \in[9.9 ; 14.2]$ Myrs for old and stiff slabs. Hence, despite possible large variations in slab age in natural subduction zones, the adjustment-time following overriding plate velocity changes may lie in a relatively narrow range (10-35 Myrs).

Together, our results suggest that the relative poor correlation between slab dip and the overriding plate velocity in present-day subduction zones (Lallemand et al. 2005) may be a consequence of most subduction zones still accommodating changes in kinematic boundary conditions that may have occurred in the last $\sim 10-35$ Myrs.

\subsubsection{Slab-dip variations and overriding plate tectonics}

Lallemand et al. (2005) showed the relatively large variety of tectonic regimes of overriding plates in present-day subduction zones and proposed a relationship between slab dip and tectonics. Heuret and Lallemand (2005) and Heuret et al. (2007) proposed a correlation between the overriding plate tectonics and its velocity (see also Arcay et al. 2008). Although our results are in good agreement with these general observations, we discuss below why past variations in plates' kinematics should also be taken into account when studying tectonics.

Our models with constant overriding plate velocities exhibit some range of tectonic regimes (value of horizontal force within the overriding plate) after slab anchoring. As described earlier, the overriding plate stress regime in those models results from the difference between the imposed kinematics and the equivalent free-overriding plate (free-trench) ve- 
locity. The larger the applied overriding plate velocity, the larger the compressive force that applies on the plate. These results are in good agreement with the conclusions of Heuret et al. (2007). The results also suggest that the large range of (non-neutral) tectonic regimes observed on Earth might indicate that the overriding plate motion does not only respond to the free rate of trench retreat. In Nature indeed, overriding plate kinematics is not only driven by the rate of free-trench retreat of individual slab segments, and the overriding plate motion largely affects the tectonic regime as proposed by Silver et al. (1998). In fact, many parameters influence the free rate of trench motion and, in turn, the tectonic regimes. For instance, the comparison between Models Aa and Na emphasizes the role that the long-term interplate friction may exert on tectonics. In the Andean margin for instance, a latitudinal variation in interplate friction has been proposed to explain the topographic segmentation observed in the Andes (Lamb and Davis 2003; Sobolev and Babeyko 2005) although other factors may have also contributed to the differences in orogen morphology (Espurt et al. 2008; Ramos 2009; Gerbault et al. 2009; Martinod et al. 2010; Capitanio et al. 2011; Cerpa et al. 2015; Schellart 2008b). .

We explore in Models Aa3.0_4.2 and Na3.0_4.2 the effects of temporal variations in overriding plate velocity and in slab dip on overriding plate tectonics. Those models predict an important decrease of extension (or increase of compression) following an increase in the overriding plate trenchward velocity. After the tectonic pulse occurring during the adjustment-time, the horizontal tectonic force within the overriding plate recovers a steadystate value. Our models predict that the force resulting from the adjustment of the slab geometry following a $1.2 \mathrm{~cm} / \mathrm{yr}$ increase in overriding plate velocity may reach $2 \times 10^{12} \mathrm{~N} / \mathrm{m}$ which is comparable to the forces per unit length that major mountain belts exert on the adjacent lithospheric plates (Molnar et al. 1993). This major result of our study emphasizes the important role of changes in overriding plate motion and temporal variations in slab dip. Also, this provides a mechanism that may partly explain why, in contrast with the conclusions of Heuret et al. (2007), some studies have found that present-day overriding 
plate motion may not be correlated with overriding plate tectonics (Schellart 2008c) : The present-day state of stresses within the overriding plate may be the temporary response to a recent kinematic change.

Further, in Models Aa3.0_4.2 and Na3.0_4.2, the minimum extension (or maximum compression) following an acceleration of the overriding plate occurs when the time-derivative of slab dip is the highest (Fig. 11). Hence, the magnitude of the pulse in the horizontal force $F_{x x}$ induced by a kinematic change depends on both the adjustment-time and the amplitude of variation in slab dip during this time. As shown in Section 4.1.1, in the case of an acceleration, a large value of change in overriding plate velocity induces a relatively small adjustment-time (Fig. 6) and a relatively large change in mean slab dip (Fig. 7). Strong accelerations may thus generate relatively large variations in overriding plate tectonics. As a consequence, important shifts in the tectonic regimes of overriding plates reported by several studies (e.g. Clark et al. 2008) might have been triggered by rapid plate kinematic reconfigurations.

\section{CONCLUSIONS}

We investigated the effects of variations in overriding plate velocity on slab dip. Following a change in the kinematics of the overriding plate, a time of adjustment is needed for the system to accommodate the new boundary conditions. Our modeling results showed a linear correlation between the adjustment-time of slab dip and the change in overriding plate velocity. Internal parameters also influence the adjustment-time. Plates and mantle viscosities increase adjustment-time while the density contrast and subducting plate thickness diminish it. The strength of the overriding plate only exerts a minor control on the adjustment-time. Within the range of external and internal parameters tested, we predict adjustment-times, i.e. the time after which $95 \%$ of the variation has been accommodated, between 5 and 65 Myrs but we suggest that the adjustment-times for natural subduction zones may be more reasonably of the order of 10-35 Myrs. Estimations from plates' kinematics models for 
28 N. G. Cerpa, B. Guillaume, J. Martinod

the last 20 Ma suggest that a relatively large number of subduction zones may not be at steady-state in present-day, owing to changes in past and recent overriding plate kinematics. Further, the models suggest that the overriding plate's tectonic regime is largely impacted by a change in overriding plate kinematics. The transient stress regime maintains as long as the slab geometry has not been adjusted to the new boundary conditions. We thus stress the importance of taking into account the past plates' kinematics when studying present-day subduction dynamics and active margin tectonics.

\section{ACKNOWLEDGMENTS}

We thank H. Č́źžková and an anonymous reviewer for their constructive comments that helped to improve the manuscript. 


\section{REFERENCES}

R. Agrusta, S. Goes, and J. van Hunen. Subducting-slab transition-zone interaction: Stagnation, penetration and mode switches. Earth and Planetary Science Letters, 464:10-23, 2017. doi: 10.1016/j.epsl.2017.02.005.

D. Arcay, S. Lallemand, and M.-P. Doin. Back-arc strain in subduction zones: Statistical observations versus numerical modeling. Geochemistry, Geophysics, Geosystems, 9(5), 2008.

N. Bellahsen, C. Faccenna, and F. Funiciello. Dynamics of subduction and plate motion in laboratory experiments: insights into the plate tectonics behavior of the earth. Journal of Geophysical Research: Solid Earth (1978-2012), 110(B1), 2005. doi: 10.1029/2004JB002999.

M. I. Billen and G. Hirth. Rheologic controls on slab dynamics. Geochemistry, Geophysics, Geosystems, 8(8), 2007. doi: 10.1029/2007GC001597.

M.-A. Bonnardot, R. Hassani, and E. Tric. Numerical modelling of lithosphereasthenosphere interaction in a subduction zone. Earth and Planetary Science Letters, 272(34):698-708, 2008. ISSN 0012-821X. doi: 10.1016/j.epsl.2008.06.009.

N. P. Butterworth, L. Quevedo, G. Morra, and R. D. Müller. Influence of overriding plate geometry and rheology on subduction. Geochemistry, Geophysics, Geosystems, 13(6), 2012. doi: 10.1029/2011GC003968.

F. A. Capitanio, D. Stegman, L.-N. Moresi, and W. Sharples. Upper plate controls on deep subduction, trench migrations and deformations at convergent margins. Tectonophysics, 483(1): 80-92, 2010. doi: 10.1016/j.tecto.2009.08.020.

F. A. Capitanio, C. Faccenna, S. Zlotnik, and D. R. Stegman. Subduction dynamics and the origin of andean orogeny and the bolivian orocline. Nature, 480(7375):83, 2011. doi: 10.1038/nature10596.

F.A. Capitanio, G. Morra, and S. Goes. Dynamic models of downgoing plate-buoyancy driven subduction: Subduction motions and energy dissipation. Earth and Planetary Science Letters, 262(1):284-297, 2007. doi: 10.1016/j.epsl.2007.07.039.

N. G. Cerpa, R. Hassani, M. Gerbault, and J.-H. Prévost. A fictitious domain method for lithosphere-asthenosphere interaction: Application to periodic slab folding in the upper mantle. Geochemistry, Geophysics, Geosystems, 15(5):1852-1877, 2014. doi: 10.1002/2014GC005241.

N. G. Cerpa, R. Araya, M. Gerbault, and R. Hassani. Relationship between slab dip and topography segmentation in an oblique subduction zone: Insights from numerical modeling. Geophysical Research Letters, 42(14):5786-5795, 2015. doi: 10.1002/2015GL064047.

U. R. Christensen. The influence of trench migration on slab penetration into the lower mantle. Earth and Planetary Science Letters, 140(1):27-39, 1996. doi: 10.1016/0012-821X(96)00023-4.

H. Č́žzová and C. Bina. Effects of mantle and subduction-interface rheologies on slab stag- 
nation and trench rollback. Earth and Planetary Science Letters, 379:95-103, 2013. doi: 10.1016/j.epsl.2013.08.011.

S. Clark, D. Stegman, and R.r Müller. Episodicity in back-arc tectonic regimes. Physics of the Earth and Planetary Interiors, 171(1):265-279, 2008. doi: 10.1016/j.pepi.2008.04.012.

M. Cloos. Lithospheric buoyancy and collisional orogenesis: Subduction of oceanic plateaus, continental margins, island arcs, spreading ridges, and seamounts. Geological Society of America Bulletin, 105(6):715-737, 1993. doi: 10.1130/0016-7606(1993)105¡0715:LBACOS ¿2.3.CO;2.

C. Cruciani, E. Carminati, and C. Doglioni. Slab dip vs. lithosphere age: no direct function. Earth and Planetary Science Letters, 238(3):298-310, 2005. doi: 10.1016/j.epsl.2005.07.025.

C. Doglioni, P. Harabaglia, S. Merlini, F. Mongelli, A. Peccerillo, and C. Piromallo. Orogens and slabs vs. their direction of subduction. Earth-Science Reviews, 45(3-4):167-208, 1999. doi: 10.1016/S0012-8252(98)00045-2.

N. Espurt, F. Funiciello, J. Martinod, B. Guillaume, V. Regard, C. Faccenna, and S. Brusset. Flat subduction dynamics and deformation of the south american plate: Insights from analog modeling. Tectonics, 27(3), 2008. doi: 10.1029/2007TC002175.

C. Faccenna, T. W. Becker, C. P. Conrad, and L. Husson. Mountain building and mantle dynamics. Tectonics, 32(1):80-93, 2013. doi: 10.1029/2012TC003176.

C. Faccenna, O. Oncken, A. F. Holt, and T. W. Becker. Initiation of the andean orogeny by lower mantle subduction. Earth and Planetary Science Letters, 463:189-201, 2017. doi: 10.1016/j.epsl.2017.01.041.

E. Ficini, L. Dal Zilio, C. Doglioni, and T. V. Gerya. Horizontal mantle flow controls subduction dynamics. Scientific Reports, 7(1):7550, 2017. doi: 10.1038/s41598-017-06551-y.

Y. Fukao and M. Obayashi. Subducted slabs stagnant above, penetrating through, and trapped below the $660 \mathrm{~km}$ discontinuity. Journal of Geophysical Research: Solid Earth, 118(11):59205938, 2013. doi: 10.1002/2013JB010466.

F. Funiciello, G. Morra, K. Regenauer-Lieb, and D. Giardini. Dynamics of retreating slabs: 1. insights from two-dimensional numerical experiments. Journal of Geophysical Research: Solid Earth (1978-2012), 108(B4), 2003. doi: 10.1029/2001JB000898.

F. Funiciello, C. Faccenna, and D. Giardini. Role of lateral mantle flow in the evolution of subduction systems: insights from laboratory experiments. Geophysical Journal International, 157(3):1393-1406, 2004. doi: 10.1111/j.1365-246X.2004.02313.x.

F Funiciello, C Faccenna, A Heuret, Serge Lallemand, E Di Giuseppe, and TW Becker. Trench migration, net rotation and slab-mantle coupling. Earth and Planetary Science Letters, 271(1): 233-240, 2008. doi: 10.1016/j.epsl.2008.04.006.

F. Garel, S. Goes, D. Davies, J. Davies, S. Kramer, and C. Wilson. Interaction of subducted 
slabs with the mantle transition-zone: A regime diagram from 2-d thermo-mechanical models with a mobile trench and an overriding plate. Geochemistry, Geophysics, Geosystems, 2014. doi: 10.1002/2014GC005257.

M. Gerbault, J. Cembrano, C. Mpodozis, M. Farias, and M. Pardo. Continental margin deformation along the andean subduction zone: Thermo-mechanical models. Physics of the Earth and Planetary Interiors, 177(3):180-205, 2009. doi: 10.1016/j.pepi.2009.09.001.

G. Gibert, M. Gerbault, R. Hassani, and E. Tric. Dependency of slab geometry on absolute velocities and conditions for cyclicity: insights from numerical modelling. Geophysical Journal International, 189(2):747760, 2012. ISSN 1365-246X. doi: 10.1111/j.1365-246X.2012.05426.x.

S. Goes, F. A. Capitanio, G. Morra, M. Seton, and D. Giardini. Signatures of downgoing platebuoyancy driven subduction in cenozoic plate motions. Physics of the Earth and Planetary Interiors, 184(1):1-13, 2011. doi: 10.1016/j.pepi.2010.10.007.

S. Goes, R. Agrusta, J. Van Hunen, and F. Garel. Subduction-transition zone interaction: A review. Geosphere, 13(3):644-664, 2017. doi: 10.1130/GES01476.1.

R. W. Griffiths, R. I. Hackney, and R. D. van der Hilst. A laboratory investigation of effects of trench migration on the descent of subducted slabs. Earth and Planetary Science Letters, 133 (1-2):1-17, 1995. doi: 10.1016/0012-821X(95)00027-A.

B. Guillaume, J. Martinod, and N. Espurt. Variations of slab dip and overriding plate tectonics during subduction: insights from analogue modelling. Tectonophysics, 463(1):167-174, 2009. doi: 10.1016/j.tecto.2008.09.043.

B. Guillaume, S. Hertgen, J. Martinod, and N. Cerpa. Slab dip, surface tectonics: How and when do they change following an acceleration/slow down of the overriding plate? Tectonophysics, 726:110-120, 2018. doi: 10.1016/j.tecto.2018.01.030.

M. Haschke, A. Günther, D. Melnick, H. Echtler, K.-J. Reutter, E. Scheuber, and O. Oncken. Central and southern andean tectonic evolution inferred from arc magmatism. In The Andes, pages 337-353. Springer, 2006.

R. Hassani, D. Jongmans, and J. Chéry. Study of plate deformation and stress in subduction processes using two-dimensional numerical models. Journal of Geophysical Research: Solid Earth, 102(B8):1795117965, 1997. ISSN 2156-2202. doi: 10.1029/97JB01354.

A. Heuret and S. Lallemand. Plate motions, slab dynamics and back-arc deformation. Physics of the Earth and Planetary Interiors, 149(1):31-51, 2005. doi: 10.1016/j.pepi.2004.08.022.

A. Heuret, F. Funiciello, C. Faccenna, and S. Lallemand. Plate kinematics, slab shape and backarc stress: a comparison between laboratory models and current subduction zones. Earth and Planetary Science Letters, 256(3):473-483, 2007. doi: 10.1016/j.epsl.2007.02.004.

A. Holt, T. Becker, and B. Buffett. Trench migration and overriding plate stress in dy- 
namic subduction models. Geophysical Journal International, 201(1):172-192, 2015. doi: $10.1093 /$ gji/ggv011.

A. Holt, L. Royden, and T. Becker. The dynamics of double slab subduction. Geophysical Journal International, 209(1):250-265, 2017. doi: 10.1093/gji/ggw496.

L. Husson, C. Conrad, and C. Faccenna. Plate motions, andean orogeny, and volcanism above the south atlantic convection cell. Earth and Planetary Science Letters, 317:126-135, 2012. doi: 10.1016/j.epsl.2011.11.040.

R. D. Jarrard. Relations among subduction parameters. Reviews of Geophysics, 24(2):217-284, 1986. doi: 10.1029/RG024i002p00217.

L. Jolivet, C. Faccenna, N. DAgostino, M. Fournier, and D. Worrall. The kinematics of back-arc basins, examples from the tyrrhenian, aegean and japan seas. Geological Society, London, Special Publications, 164(1):21-53, 1999. doi: 10.1144/GSL.SP.1999.164.01.04.

Á. Király, F. A. Capitanio, F. Funiciello, and C. Faccenna. Subduction zone interaction: Controls on arcuate belts. Geology, 44(9):715-718, 2016. doi: 10.1130/G37912.1.

S. Lallemand, A. Heuret, and D. Boutelier. On the relationships between slab dip, back-arc stress, upper plate absolute motion, and crustal nature in subduction zones. Geochemistry, Geophysics, Geosystems, 6(9), 2005. doi: 10.1029/2005GC000917.

S. Lamb and P. Davis. Cenozoic climate change as a possible cause for the rise of the andes. Nature, 425(6960):792-797, 2003. doi: 10.1038/nature02049.

H. Lau, J. Mitrovica, J. Austermann, O. Crawford, D. Al-Attar, and K. Latychev. Inferences of mantle viscosity based on ice age data sets: Radial structure. Journal of Geophysical Research: Solid Earth, 121(10):6991-7012, 2016. doi: 10.1002/2016JB013043.

C. Loiselet, L. Husson, and J. Braun. From longitudinal slab curvature to slab rheology. Geology, 37(8):747-750, 2009. doi: 10.1130/G30052A.1.

J. Martinod, L. Husson, P. Roperch, B. Guillaume, and N. Espurt. Horizontal subduction zones, convergence velocity and the building of the andes. Earth and Planetary Science Letters, 299 (3):299-309, 2010. doi: 10.1016/j.epsl.2010.09.010.

J. Mitrovica and A. Forte. A new inference of mantle viscosity based upon joint inversion of convection and glacial isostatic adjustment data. Earth and Planetary Science Letters, 225(1): 177-189, 2004. doi: 10.1016/j.epsl.2004.06.005.

P. Molnar, P. England, and J. Martinod. Mantle dynamics, uplift of the tibetan plateau, and the indian monsoon. Reviews of Geophysics, 31(4):357-396, 1993. doi: 10.1029/93RG02030.

G. Morra and K. Regenauer-Lieb. A coupled solid-fluid method for modelling subduction. Philosophical magazine, 86(21-22):3307-3323, 2006.

R. D. Müller, M. Seton, S. Zahirovic, S. E. Williams, K. J. Matthews, N. M. Wright, G. E. 
Shephard, K. T. Maloney, N. Barnett-Moore, M. Hosseinpour, et al. Ocean basin evolution and global-scale plate reorganization events since pangea breakup. Annual Review of Earth and Planetary Sciences, 44:107-138, 2016. doi: 10.1146/annurev-earth-060115-012211.

D. Olbertz, M.J.R. Wortel, and U. Hansen. Trench migration and subduction zone geometry. Geophysical Research Letters, 24(3):221-224, 1997. doi: 10.1029/96GL03971.

F. Pardo-Casas and P. Molnar. Relative motion of the nazca (farallon) and south american plates since late cretaceous time. Tectonics, 6(3):233-248, 1987. doi: 10.1029/TC006i003p00233.

A. Paulson, S. Zhong, and J. Wahr. Inference of mantle viscosity from grace and relative sea level data. Geophysical Journal International, 171(2):497-508, 2007. doi: 10.1111/j.1365246X.2007.03556.x.

V. A. Ramos. Anatomy and global context of the andes: Main geologic features and the andean orogenic cycle. Geological Society of America Memoirs, 204:31-65, 2009.

N. M. Ribe. Bending mechanics and mode selection in free subduction: a thin-sheet analysis. Geophysical Journal International, 180(2):559-576, 2010. doi: 10.1111/j.1365-246X.2009.04460.x.

J. Rodríguez-González, A. Negredo, and M. Billen. The role of the overriding plate thermal state on slab dip variability and on the occurrence of flat subduction. Geochemistry, Geophysics, Geosystems, 13(1), 2012. doi: 10.1029/2011GC003859.

W. Schellart, J. Freeman, D. Stegman, L. Moresi, and D. May. Evolution and diversity of subduction zones controlled by slab width. Nature, 446(7133):308-311, 2007. doi: 10.1038/nature05615.

W. P. Schellart. Kinematics and flow patterns in deep mantle and upper mantle subduction models: Influence of the mantle depth and slab to mantle viscosity ratio. Geochemistry, Geophysics, Geosystems, 9(3), 2008a. doi: 10.1029/2004JB002970.

W. P. Schellart. Overriding plate shortening and extension above subduction zones: A parametric study to explain formation of the andes mountains. Geological Society of America Bulletin, 120 (11-12):1441-1454, 2008b.

W. P. Schellart. Subduction zone trench migration: Slab driven or overriding-plate-driven? Physics of the Earth and Planetary Interiors, 170(1-2):73-88, 2008c.

W.P. Schellart. Kinematics of subduction and subduction-induced flow in the upper mantle. Journal of Geophysical Research: Solid Earth (1978-2012), 109(B7), $2004 . \quad$ doi: 10.1029/2004JB002970.

M. Sdrolias and R. Müller. Controls on back-arc basin formation. Geochemistry, Geophysics, Geosystems, 7(4), 2006. doi: 10.1029/2005GC001090.

W. Sharples, M. Jadamec, L. Moresi, and F. Capitanio. Overriding plate controls on subduction evolution. Journal of Geophysical Research: Solid Earth, 119(8):6684-6704, 2014. doi: 10.1002/2014JB011163. 
P. Silver, R. Russo, and C. Lithgow-Bertelloni. Coupling of south american and african plate motion and plate deformation. Science, 279(5347):60-63, 1998. doi: 10.1126/science.279.5347.60.

S. V. Sobolev and A. Y. Babeyko. What drives orogeny in the andes? Geology, 33(8):617-620, 2005. doi: 10.1130/G21557AR.1.

D. Stegman, R. Farrington, F. A. Capitanio, and W. P. Schellart. A regime diagram for subduction styles from 3-d numerical models of free subduction. Tectonophysics, 483(1):29-45, 2010. doi: 10.1016/j.tecto.2009.08.041.

T. H. Torsvik, R. D. Müller, R. Van der Voo, B. Steinberger, and C. Gaina. Global plate motion frames: toward a unified model. Reviews of geophysics, 46(3), 2008. doi: 10.1029/2007RG000227.

D. L. Turcotte and G. Schubert. Geodynamics. Cambridge Univ. Press, New York, 2002.

Y. van Dinther, G. Morra, F. Funiciello, and C. Faccenna. Role of the overriding plate in the subduction process: Insights from numerical models. Tectonophysics, 484(1):74-86, 2010. doi: 10.1016/j.tecto.2009.08.038.

B. Wu, C. Conrad, A. Heuret, C. Lithgow-Bertelloni, and S. Lallemand. Reconciling strong slab pull and weak plate bending: The plate motion constraint on the strength of mantle slabs. Earth and Planetary Science Letters, 272(1):412-421, 2008. doi: 10.1016/j.epsl.2008.05.009.

P. Yamato, L. Husson, J. Braun, C. Loiselet, and C. Thieulot. Influence of surrounding plates on 3d subduction dynamics. Geophysical Research Letters, 36(7), 2009. doi: 10.1029/2008GL036942.

S. Zahirovic, R. D. Müller, M. Seton, and N. Flament. Tectonic speed limits from plate kinematic reconstructions. Earth and Planetary Science Letters, 418:40-52, 2015. doi: 10.1016/j.epsl.2015.02.037. 


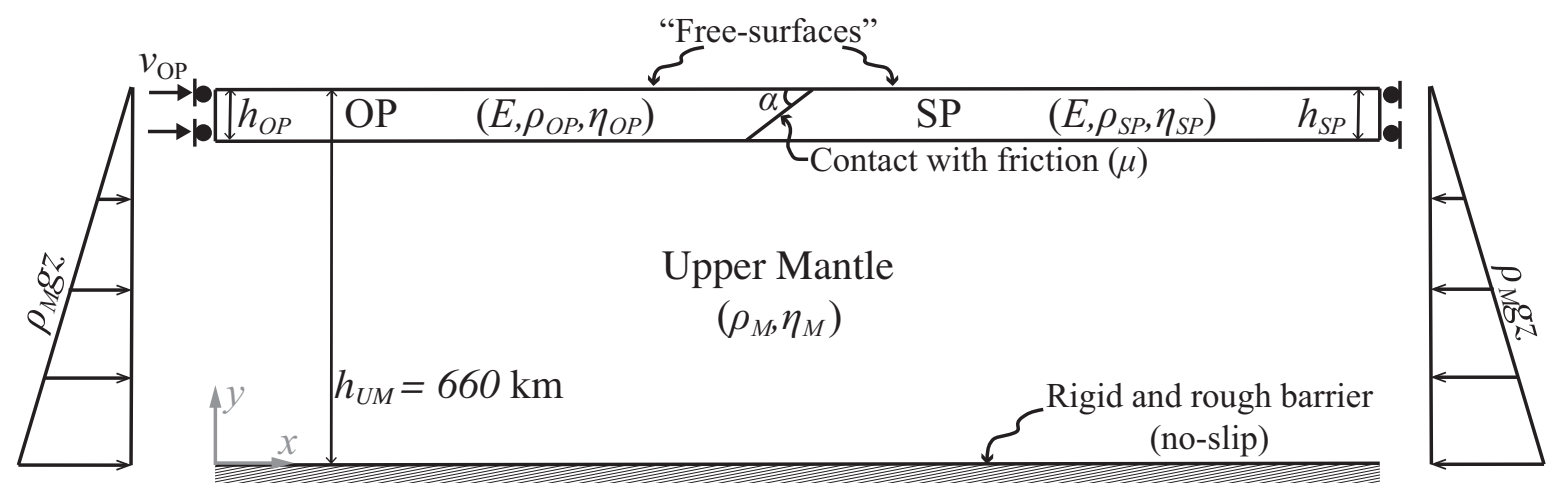

Figure 1. Schematic initial configuration of the models with mechanical parameters and boundary conditions. Throughout this study, all velocities are expressed in the fixed reference frame attached to the impermeable bottom boundary, that is an immobile-lower mantle reference frame. 


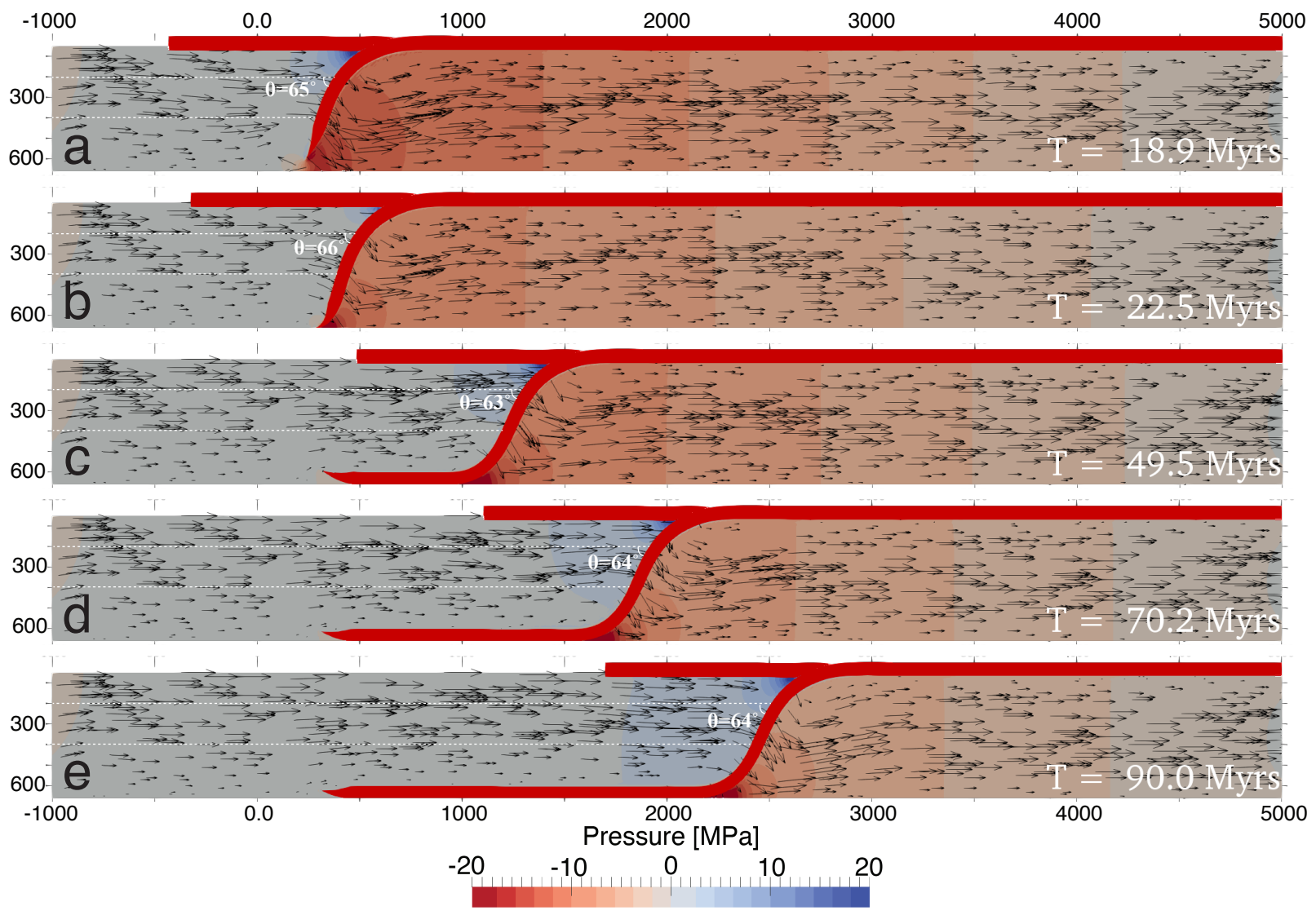

Figure 2. Time-evolution snapshots of Model A3.0. Color scale is dynamic pressure. Black arrows are velocity field in the mantle. $\theta$ is the averaged slab dip between 200 and $400-\mathrm{km}$ depths. 


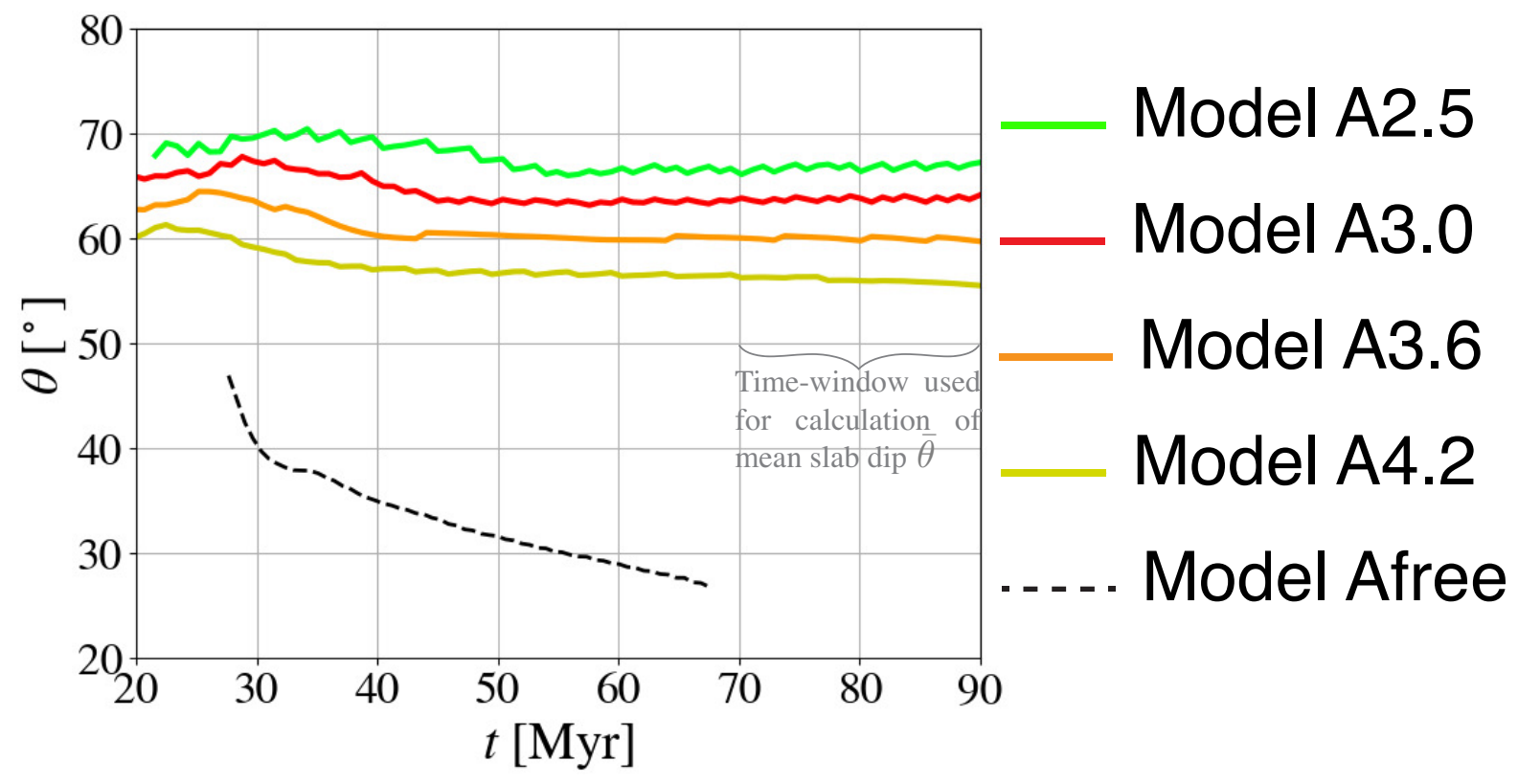

Figure 3. Slab dip at a 300-km depth for models with constant overriding plate velocity. 


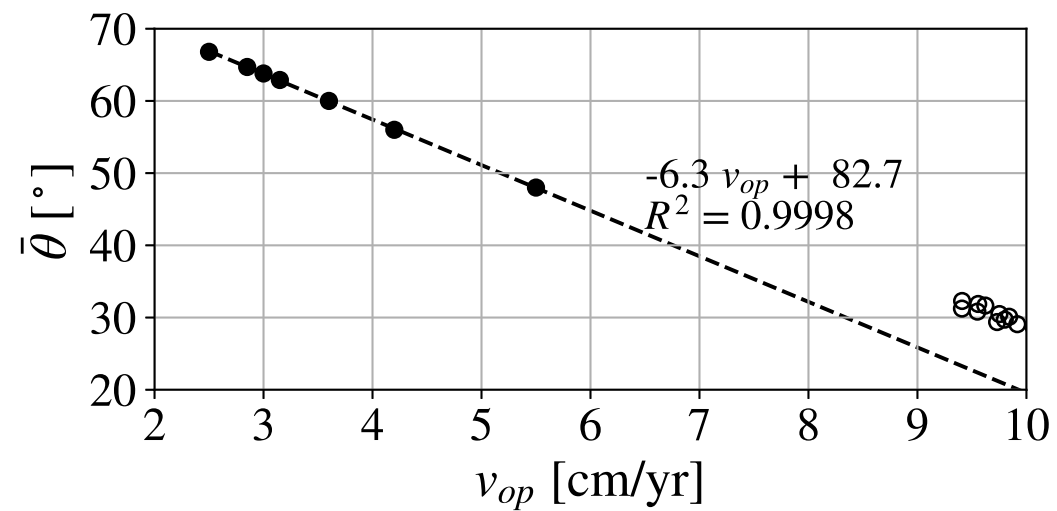

Figure 4. Mean slab dip at a 300-km depth for Models A as a function of the imposed overriding plate velocity (filled circles), and the linear regression (dashed line). Open circles represent slab dip at 300-km depth in Model Afree and are plotted against the measured free overriding plate velocity at several time steps after slab anchoring. 


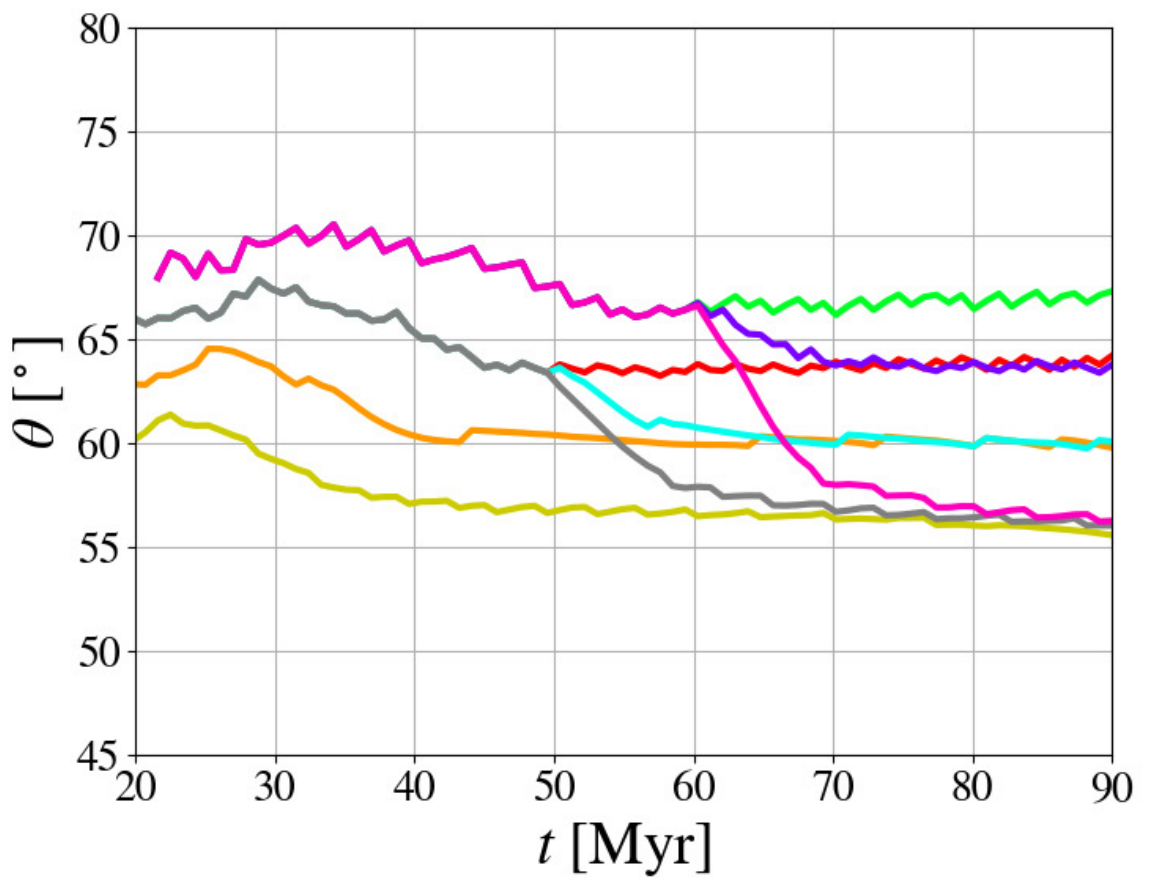

Model A2.5 - Model A2.5_3.0

Model A3.0 - Model A2.5_4.2

Model A3.6 - Model A3.0_3.6

Model A4.2 — Model A3.0_4.2

Figure 5. Slab dip measured at a 300-km depth for models with an instantaneous increase in trenchward overriding plate velocity after 50 Myrs (Models A3.0_3.6 and A3.0_4.2) or 60 Myrs (Models A2.5_3.0, A2.5_4.2). 


\section{[ht]}

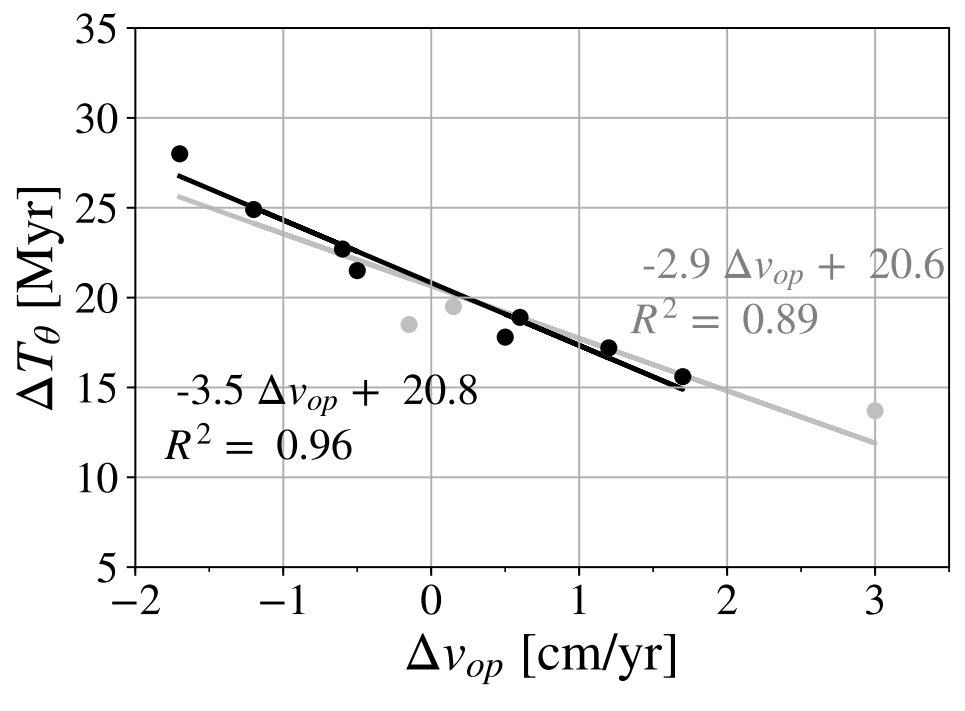

Figure 6. Adjustment-times of slab dip $\left(\Delta T_{\theta}\right)$ as a function of the velocity change $\Delta v_{o p}$. Black dots are estimated $\Delta T_{\theta}$ for Models $\mathrm{Aw}_{-} \mathrm{y}(\{\mathrm{w}, \mathrm{y}\} \in[2.5,3.0,3.6,4.2])$ and grey dots are for all Models $\mathrm{A}$. The solid line is linear-regression fit. 


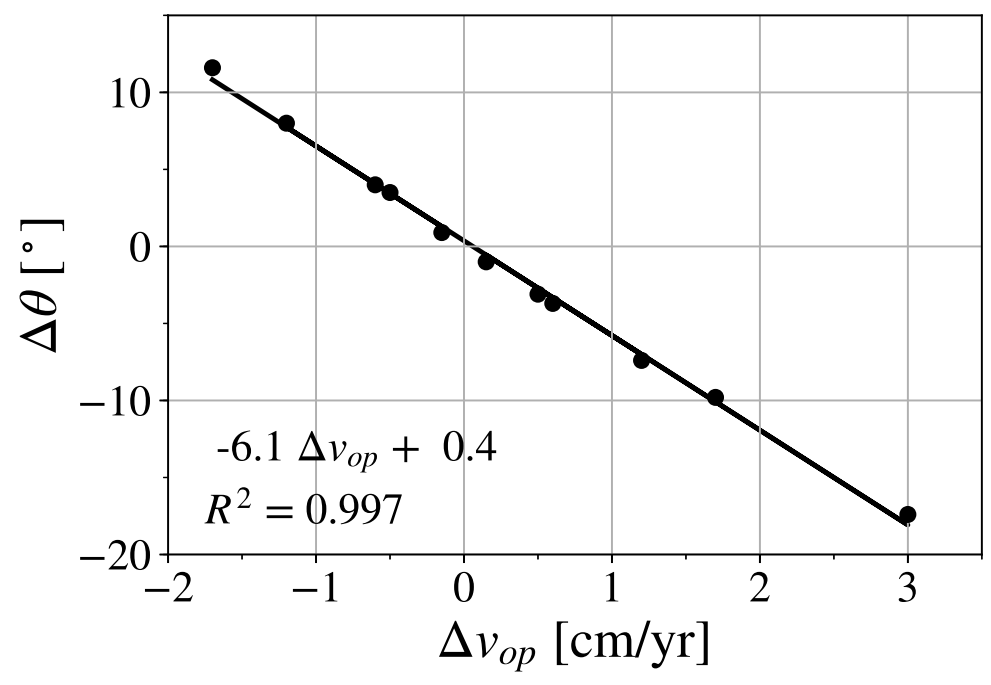

[ht]

Figure 7. Total change in slab dip $(\Delta \theta)$ during the adjustment-time as a function of the change in overriding plate velocity $\left(\Delta v_{o p}\right)$ inferred from Models A. The total change in slab dip is calculated as the difference in mean slab dip $(\bar{\theta})$ between Model A $w_{-} y$ and Model Ay. Black dots are the calculated $\Delta \theta$ for each Model $\mathrm{A} w_{-} y$ and black solid line is the regression line. 
- Model A3.0

- Model A3.6

— Model A3.0_3.6_05 Model A3.0_3.6_10

— Model A3.0_3.6 - Model A3.0_3.6_20
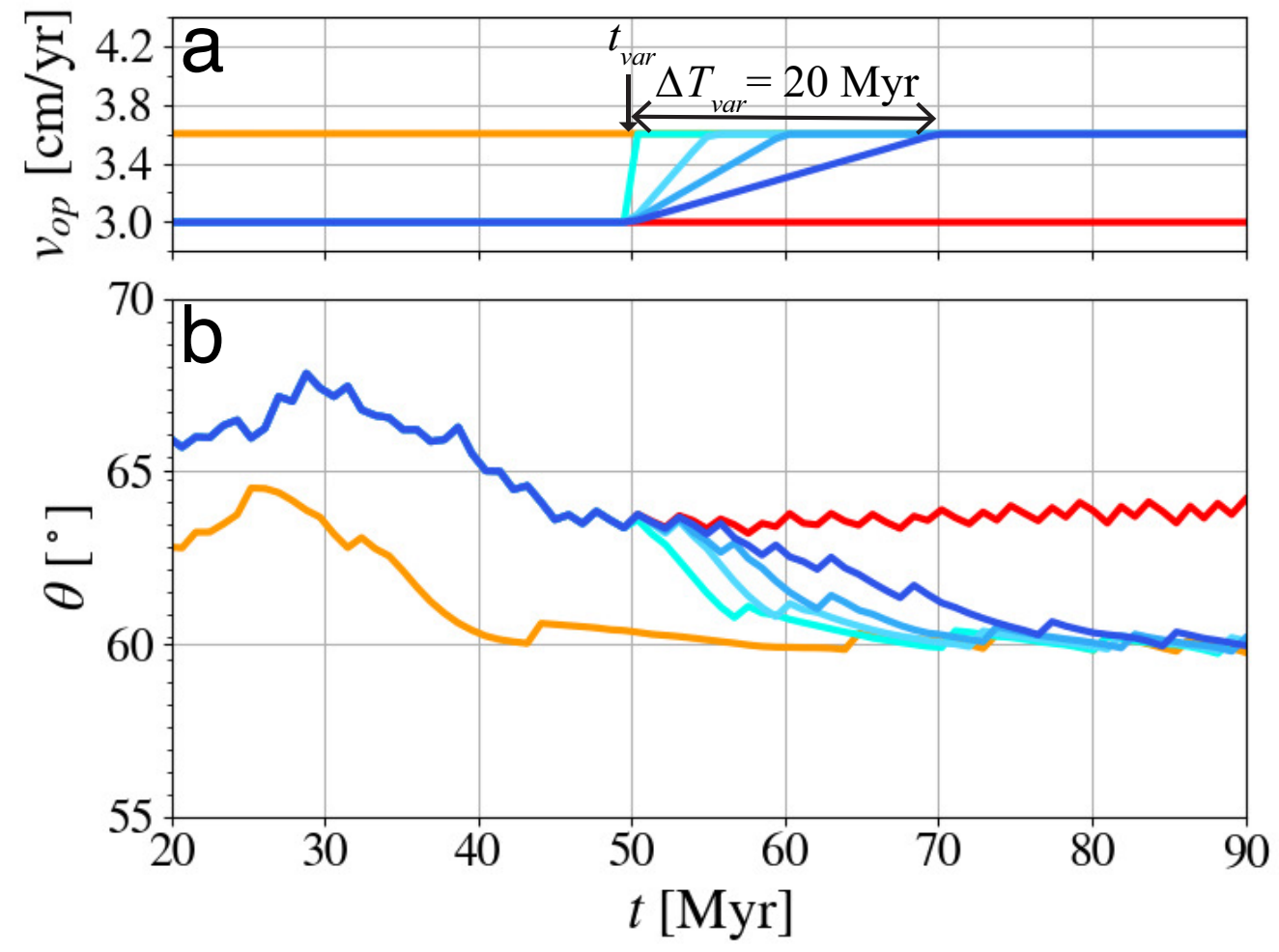

Figure 8. a) Imposed overriding plate velocity. b) Slab dip at a 300-km depth. 

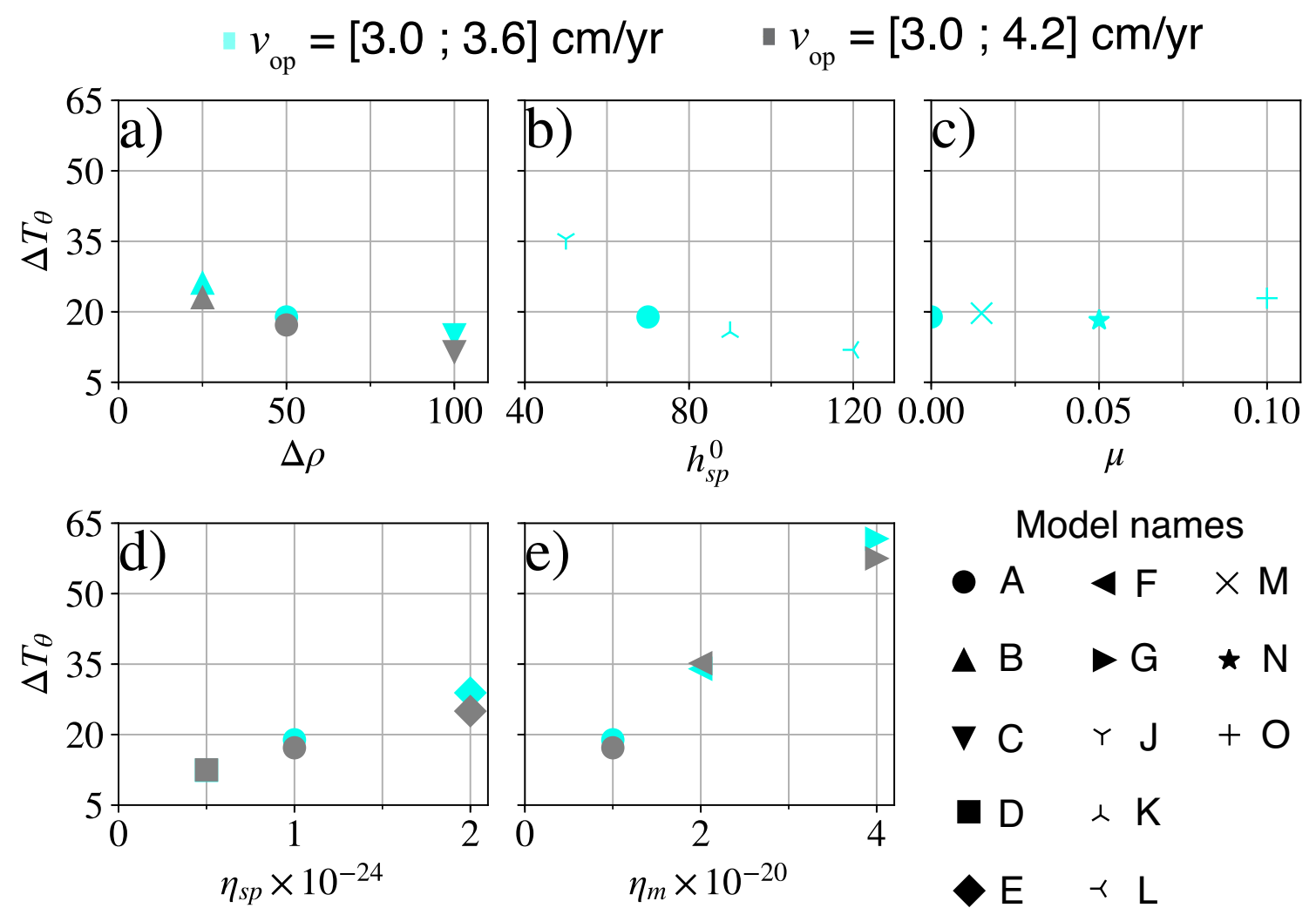

Model names

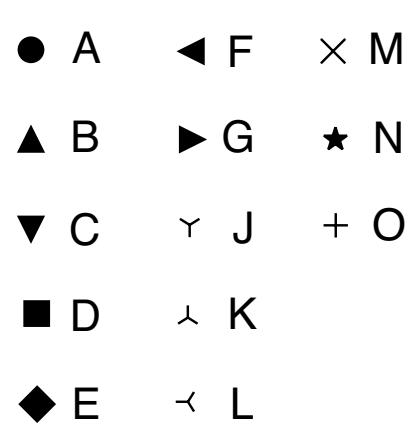

Figure 9. Influence of subducting plate internal parameters on adjustment-time $\Delta T_{\theta}$. In each subplot, the y-axis represents the adjustment-time in Myr. From left to right and from top to bottom panels, the x-axis represents : a) Density contrast at the base of lithosphere (in $\mathrm{kg} \cdot \mathrm{m}^{-3}$ ). b) Initial subducting plate thickness (in $\mathrm{km}$ ). c) Interplate friction coefficient. d) Subducting plate viscosity (in $\mathrm{Pa} \mathrm{s}$ ). e) Mantle viscosity (in Pa s). Blue points correspond to $\Delta v_{o p}=0.6 \mathrm{~cm} / \mathrm{yr}$, gray points to $\Delta v_{o p}=1.2 \mathrm{~cm} / \mathrm{yr}$. 


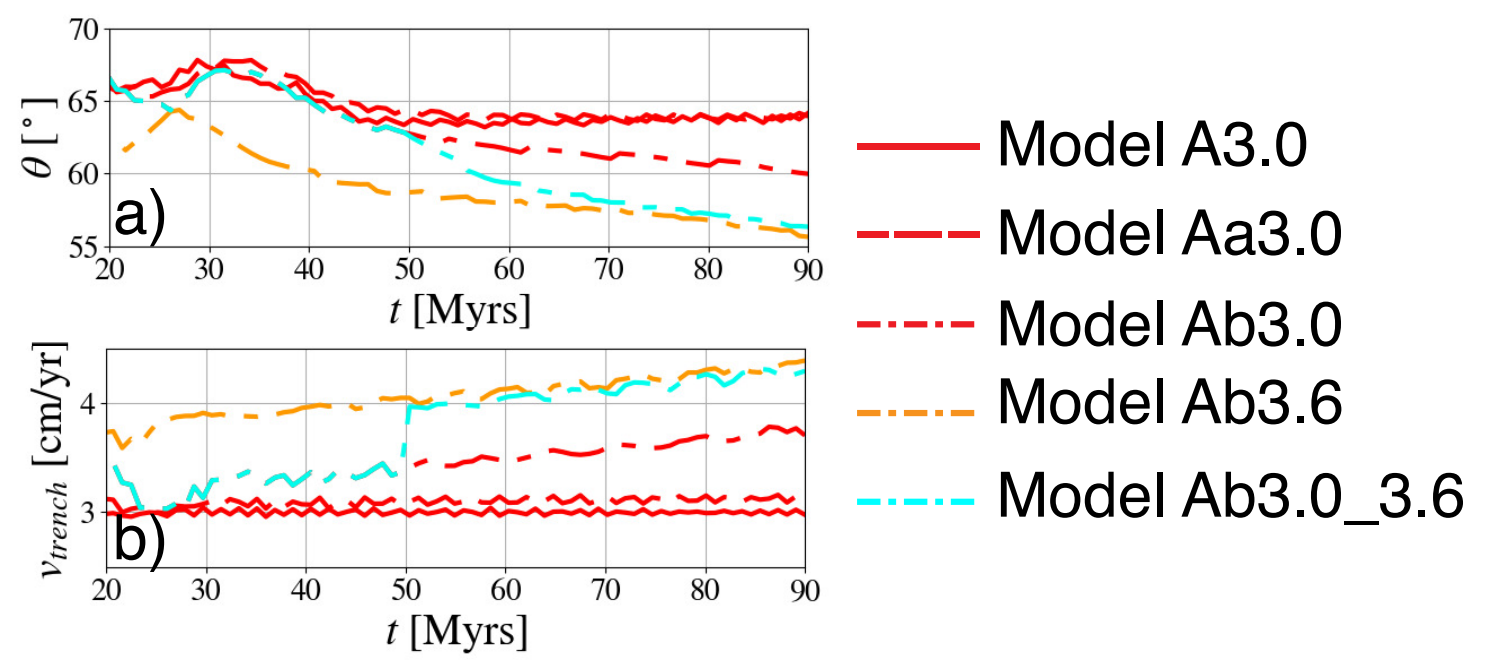

Figure 10. a) Slab dip at a 300-km depth and b) horizontal trench velocity relative to a fixed reference frame (values $>0$ indicate trench motion towards the subducting plate) for models with an overriding plate with infinite viscosity (Model A), a viscosity of $10^{24} \mathrm{~Pa}$ s (Model Aa), and a viscosity of $2.5 \times 10^{23} \mathrm{~Pa}$ s (Models $\mathrm{Ab}$ ). 


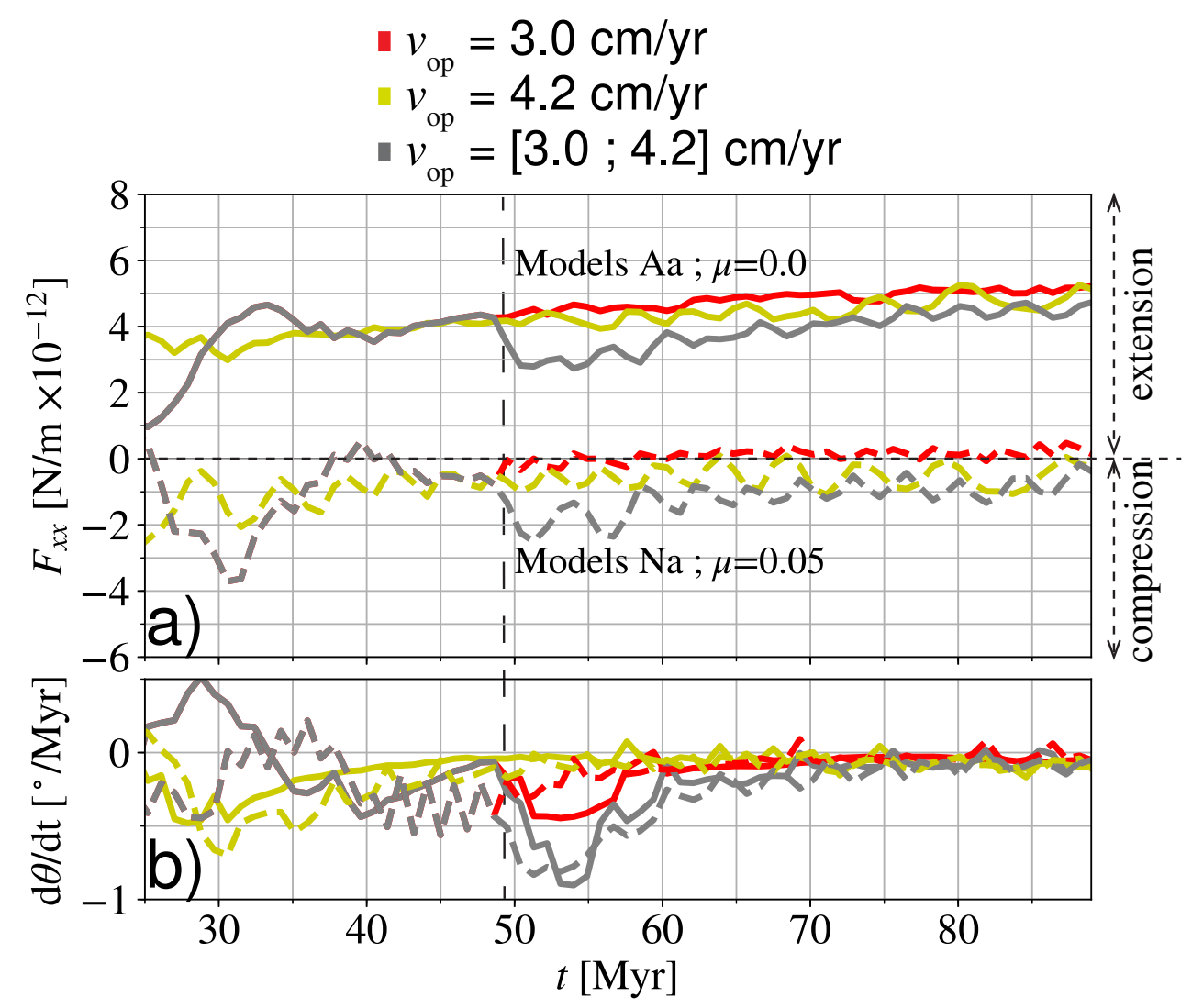

Figure 11. a) Time-evolution of the far-field average horizontal force $F_{x x}$ within the overriding plate for Models Aa and Na. The force is calculated by integrating the deviatoric stresses computed at the trailing-edge of the overriding plate. The computed value is then smoothed to filter highfrequency oscillations of the model. b) Smoothed time-derivative of slab dip. The time of increase in overriding plate velocity, when applies, is indicated by the vertical black dashed line. 


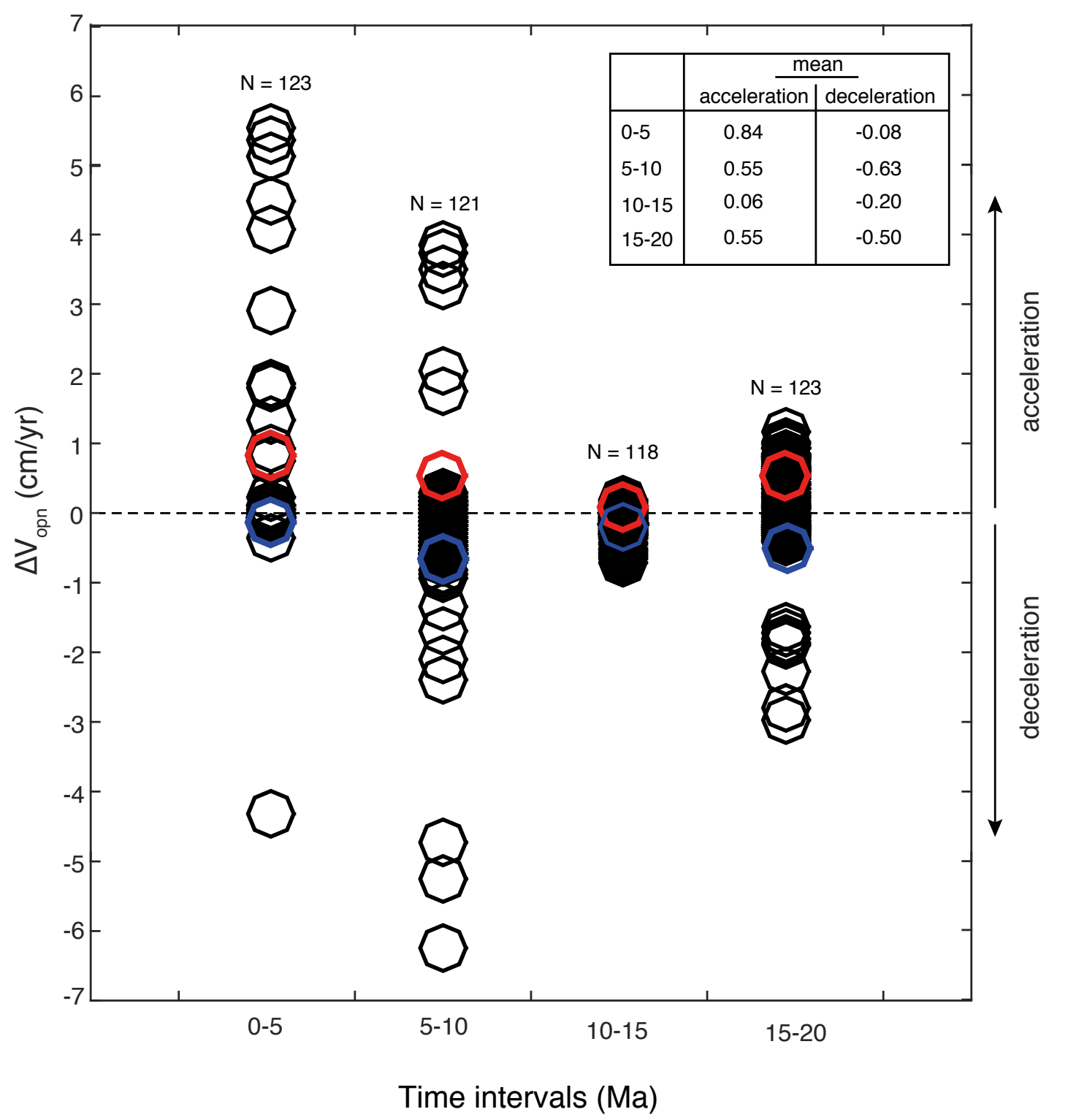

Figure 12. Changes in trench-normal overriding plate velocity for advancing overriding plates in the absolute reference frame of Torsvik et al. (2008). The velocity changes are calculated on 5 Myrs-intervals over the last 20 Myrs from the model of Müller et al. (2016) for transects (individual black circles) defined in the SUBMAP database (Heuret and Lallemand 2005). The number $N$ of transects is indicated for each interval. Mean values of changes in overriding plate velocity are indicated by red and blue circles. Their values in $\mathrm{cm} / \mathrm{yr}$ are given in the table. Note that for each time-interval we have selected all transects with advancing overriding plates and therefore the selected subduction transects may differ between the intervals. 


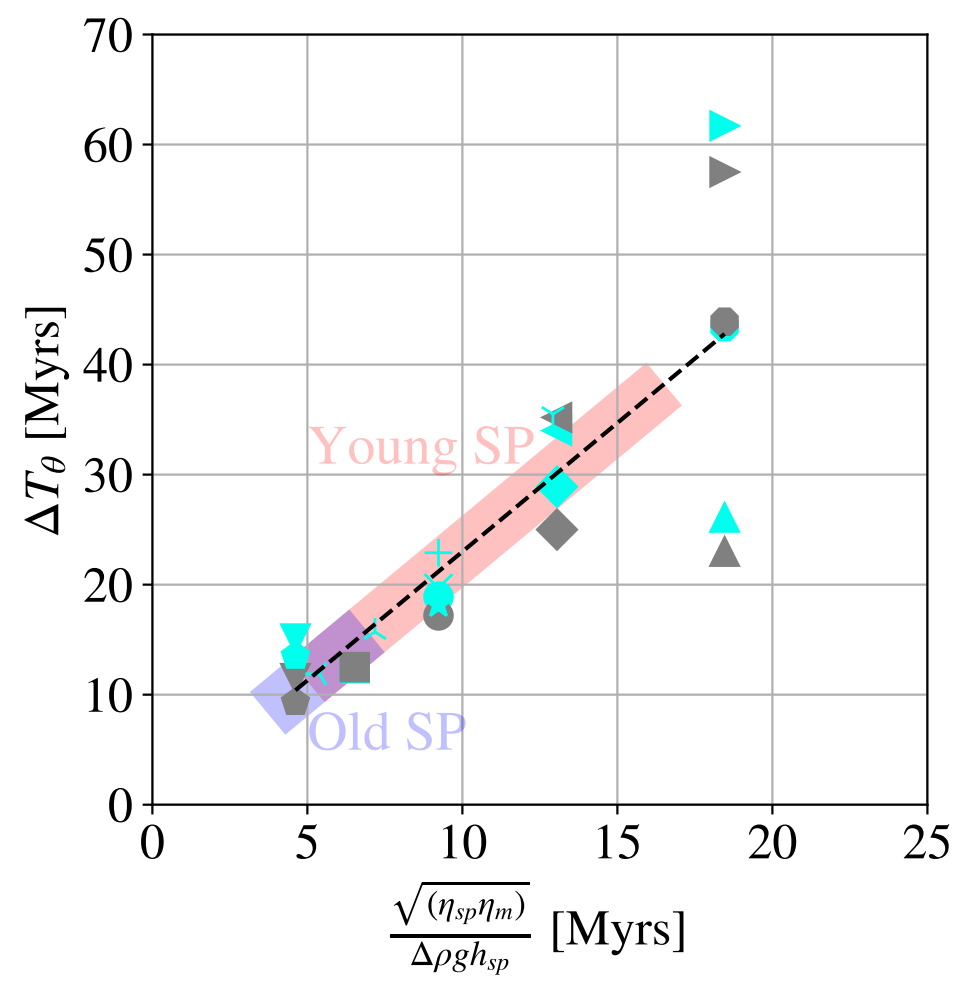

Figure 13. Adjustment-time (in Myr) as a function of the parameter $\Lambda$. Colored rectangles are estimation windows for a relatively old (110 Ma) and a relatively young (30 Ma) subducting plate as described in the text. 